\title{
The Tensile and Tensile-Creep Deformation Behavior of Ti-8Al-1Mo-1V(wt.\%)
}

\author{
I.G. Dastidar ${ }^{1}$, A.L. Pilchak ${ }^{2}$, T.R. Bieler ${ }^{1}$, V. Khademi $^{1,3}$, M.A. Crimp ${ }^{1}$, and C.J. Boehlert ${ }^{1 *}$
}

1 Department of Chemical Engineering and Materials Science, Michigan State University, East Lansing, MI, 48824, USA

2 Air Force Research Laboratory, Materials and Manufacturing Directorate, AFRL/RXCM, Wright Patterson Air Force Base, OH, 45433, USA

3 Department of Mechanical Engineering, Michigan State University, East Lansing, MI, 48824, USA

\begin{abstract}
The deformation behavior of titanium (Ti) can be complex due to the lower crystal symmetry of the hexagonal $\alpha$ phase compared with metals based on cubic phases. The tensile and tensile-creep deformation behavior of a Ti-8Al-1Mo-1V(wt.\%) alloy with a weak crystallographic texture was investigated in-situ straining scanning electron microscopy. Tensile experiments were performed at room temperature $(\mathrm{RT}), 260^{\circ} \mathrm{C}, 455^{\circ} \mathrm{C}$, and $650^{\circ} \mathrm{C}$, while tensile-creep experiments were performed at $370^{\circ} \mathrm{C}$ and $455^{\circ} \mathrm{C}$. Electron backscattered diffraction (EBSD) was performed both before and after the deformation, and slip trace analysis was used to identify the activation of the slip modes as a function of temperature and the associated global-stress-state Schmid factors. While extensive slip was characterized during the tensile tests, no twinning was observed. During the RT tensile tests the majority of the slip observed was on prismatic planes, while the relative activity of basal slip increased with temperature, such that at $455^{\circ} \mathrm{C}$, basal slip and prismatic slip were equally active. Some grain boundary and triple point cracking occurred during the elevated-temperature tensile deformation, while less slip activity and more grain boundary ledge formation were observed during the tensile-creep deformation. During tensile-creep, basal slip was more prevalent than prismatic slip and some transgranular cracks formed.
\end{abstract}

Keywords: In-situ SEM, EBSD, Tension, Creep, Titanium alloy, Deformation mode

\footnotetext{
* Corresponding author. Tel.: +1 517353 3703; fax: +1 5174321105 .

E-mail address: boehlerteegr.msu.edu (C.J. Boehlert) 


\section{INTRODUCTION}

The most common slip systems in hexagonal titanium (Ti) are basal, prismatic, pyramidal $\langle 11-20\rangle$ (i.e. $\langle a\rangle$ ), and pyramidal $\langle 11-2-3\rangle$ (i.e. $\langle\mathrm{c}+\mathrm{a}\rangle$ ) slip systems [1]. It is well accepted that is it much more difficult to activate $\langle c+a\rangle$ slip than $\langle a\rangle$ slip systems, due in part to the larger Burgers vector of $\langle c+a\rangle$ dislocations [1-5]. Compared to an ideal close packed hexagonal crystal structure, pure $\alpha$-Ti has a smaller c/a ratio, which results in the packing density of the prism planes to be larger than that on the basal planes, and this is reflected by the lower critical resolved shear stress for $<a>$ prismatic slip relative to $<a>$ basal slip $[\mathbf{4 , 6}$. As dictated by the von Mises criterion [7], for a polycrystalline material five independent slip systems are required for a grain to undergo an arbitrary imposed deformation. But because there are only three slip directions with the $\langle a\rangle$ type Burgers vectors, and none of these can result in shear in the [0001] direction, in order to satisfy the von Mises criterion $\langle c+a\rangle$ slip systems, twinning, and/or other deformation mechanisms, such as various creep mechanisms, must be activated in addition to the three $a$-type slip systems. The understanding of this complex behavior is further complicated by variations in temperature and the addition of alloying additions to Ti, which have been shown to change the relative activation of the different deformation systems [1-4,8-13]. For example, it has been shown that basal slip is more easily activated in the near- $\alpha$ and $\alpha+\beta$ alloys [2,3,11]. Teer et al. $[\mathbf{1 4}]$ concluded that $\mathrm{Al}$ and $\mathrm{Sn}$ additions cause a reduction of both a and $\mathrm{c}$, and an increase in the c/a ratio. Overall, the basal plane will be more closely packed in alloys containing $\mathrm{Al}$ and $\mathrm{Sn}$, resulting in easier activation of basal slip. Williams et al. [2] suggested that increased temperature decreases the critical resolved shear stress (CRSS) of both basal and prismatic slip for single crystal $\alpha$ Ti-xAl alloys, where $1.4<x<6.6$ (wt.\%), but that the decrease in CRSS for basal slip is more dramatic than that for prismatic slip. 
A number of groups have estimated the CRSS ratios of the different slip systems for CP-Ti and different Ti alloys (single crystal and poly-crystals) under different testing conditions [3,5,9,10, 15,16]. However there is no consensus on the CRSS ratios of commercially-pure $\mathrm{Ti}(\mathrm{CP} \mathrm{Ti})$ and different $\mathrm{Ti}$ alloys, as significant variations in the CRSS ratios are observed for different $\mathrm{Ti}$ alloys $[2-5,9-11,13,15,16]$. In addition, results from different groups are sometimes different for the same material $[\mathbf{2 - 5 , 9 - 1 1 , 1 3 , 1 5 , 1 6 ] , ~ w h i c h ~ m a y ~ r e f l e c t ~ v a r i a t i o n s ~ i n ~ m i c r o s t r u c t u r e s , ~ i m p u r i t y ~}$ content, or testing conditions. Thus, it is evident that the deformation behavior of Ti alloys depends on alloying content and identifying the CRSS values for polycrystalline Ti alloy microstructures is not trivial. Recently, Li et al. $[4,12,13]$ estimated the ambient temperature basal: prism: pyramidal<a>: pyramidal<c+a> CRSS ratios for CP-Ti (1:0.28:7.1:6.3), Ti-5Al2.5Sn (1: 0.81: 19.1: 35.5), Ti-3Al-2.5V (1: 0.16:0.81:5.7) and Ti-6Al-4V (1:1.2:13.2:38) using statistical approach based on the occurrence of surface slip traces and their associated Schmid factors based on the global stress state

The primary objective of the present study is to build on the work of Li et al., $[4,12,13]$ to study the effects of other alloying additions, specifically vanadium (V) and molybdenum (Mo), on the relative activation of different slip modes by examining the commercially important alloy Ti-8Al-1Mo-1V(wt.\%). Studies on the deformation behavior of Ti-8Al-1Mo-1V are limited. Chan [9] studied the deformation behavior of single $\alpha-\beta$ colonies of near- $\alpha$ Ti-8Al-1Mo-1V during compression testing. Jenkins and Williard [17] studied creep and rupture properties of the alloy at different temperatures. However the deformation modes of this alloy have not been well documented as a function of stress and temperature. While the large Al content would be expected to enhance the activation of basal slip, both $\mathrm{V}$ and Mo are $\beta$-phase stabilizers that increase strength [16]. But V has a similar atomic radius $(0.134 \mathrm{~nm})$ to $\mathrm{Ti}(0.147 \mathrm{~nm})[\mathbf{1 8}]$ and 
consequently does not have a large effect on the $c / a$ ratio, and would not be expected to have a strong effect on the activation of basal versus prismatic slip. Similarly, with an atomic radius of $0.139 \mathrm{~nm}$, Mo would not be expected to have a strong effect.

In the current work, in-situ SEM tensile tests and tensile-creep tests were performed on Ti-8Al-1Mo-1V under identical testing conditions as those used by $\mathrm{Li}$ et al. $[\mathbf{4 , 1 2}]$ in order to systematically characterize the surface deformation evolution to understand how alloying affects the distribution of the deformation modes. Four modes of slip were considered (basal, prism, pyramidal $\langle c+a\rangle$ and pyramidal $\langle a\rangle$ ). Grain boundary sliding and cracking, which developed during the course of testing the alloy under some conditions of temperature and stress, are also characterized. The results are discussed in relation to the relative activity of the active deformation systems in other Ti-alloys systems.

\section{EXPERIMENTAL PROCEDURES}

\subsection{Material and Microstructural Characterization}

The Ti-8Al-1Mo-1V near $\alpha$-alloy was prepared as a $12.7 \mathrm{~cm}$ diameter billet prepared by TIMET, Inc. (Henderson, Nevada). The bulk chemical composition of the alloy (Ti-7.75Al-0.97Mo-1V0.110-0.0027N(wt.\%)) was measured using inductively coupled plasma mass spectrometry (ICPMS) by NSL Analytical (Cleveland, OH). Specimens were prepared for both metallographic characterization and EBSD study using standard polishing techniques, using colloidal silica with $0.06 \mu \mathrm{m}$ particle size and one part $30 \%$ hydrogen peroxide for the final polishing step. Phase volume fractions and grain sizes were measured using secondary electron imaging (SE) carried out using a field emission gun Tescan Mira3 scanning electron microscope (SEM). The hexagonal $\alpha$ phase appeared dark or grey in the SEM images due to its low average atomic 
number ( $\mathrm{Al}$ is the most common $\alpha$-phase stabilizer and it has an atomic number of 13) while the bcc $\beta$-phase appeared brighter because it was enriched with $\mathrm{V}$ ( $\mathrm{V}$ is the most common $\beta$ stabilizer and it has an atomic number of 23) [19]. Adobe Photoshop software was used to measure the phase volume fractions. The material exhibited equiaxed $\alpha$-grains, and the grain sizes were measured using the line-intercept method [20]. Figure 5 illustrates EBSD pole figures indicating the material was not strongly textured.

\subsection{In-Situ Mechanical Testing}

Flat dog-bone specimens, with 3mm gage widths and 10mm lengths (see Figure 1), were cut by electrodischarge machining (EDM) and polished as described above. Electron backscattered diffraction (EBSD) orientation image mapping (OIM) was performed on selected areas of the gauge section of the samples both prior to and after deformation. EBSD orientation maps were obtained on samples tilted 70 degrees about the tensile axis using an EDAX-TSL (Mahwah, NJ, USA) EBSD system on the Tescan Mira3 SEM. Patterns were collected using a $25 \mathrm{kV}$ electron beam, a working distance of $\sim 20 \mathrm{~mm}$, and $2 \times 2$ binning. The EBSD scans were performed on an area of approximately $500 \mu \mathrm{m}$ by $500 \mu \mathrm{m}$, using a step sizes of $0.5-1 \mu \mathrm{m}$. After the EBSD maps were obtained, post-processing "clean-up" was performed using "Neighbor CI Correlation" to eliminate erroneous data points arising from un-indexed or inappropriately indexed patterns. "Neighbor CI Correlation" is done by replacing the orientation of the erroneous data point (generally points with confidence index values $<0.1$ ) with the orientation of the neighboring point with the highest confidence index.

The in-situ SEM tensile tests captured the surface deformation evolution (both topographic and changes in grain shape) of the specimens with increasing stress and strain at a 
constant test temperature. A screw-driven tensile stage built by Ernest F. Fullam, Inc. (originally located in Lantham, NY and later acquired by MTI Instruments, Albany, NY) was inserted inside the Tescan Mira3 SEM, as illustrated in Figure 2. A total of 4 in-situ tensile tests were performed. One test was performed at each of the following temperatures: $25^{\circ} \mathrm{C}, 260^{\circ} \mathrm{C}, 455^{\circ} \mathrm{C}$ and $650^{\circ} \mathrm{C}$. Each test was performed at a constant displacement rate of $0.004 \mathrm{~mm} / \mathrm{s}$ (i.e. an approximate strain rate of $10^{-3} \mathrm{~s}^{-1}$ ). Displacement, time, and load data were recorded during the tests using the MTESTW version F 8.8e data acquisition and control software (Admet, Inc., Norwood, MA, USA). Secondary electron (SE) images were acquired during the tests after pausing the tests at different intervals. Load relaxation occurred during this time, and the tests were resumed at the same displacement rate after imaging was completed. For the elevatedtemperature tensile tests, a $6 \mathrm{~mm}$ diameter tungsten-based heating unit, powered by a constant voltage power supply, was used to heat the samples to the desired temperature. The desired temperature, monitored using a thermocouple spot-welded to the side of the gage section, was maintained for a minimum of 30 minutes before and throughout loading. The SEM chamber vacuum was maintained below $2 \times 10^{-6}$ Torr throughout the experiments. In order to calculate local strain in the imaged area, the relative displacements of pairs of obvious microstructural features on the specimen surface were tracked.

In-situ tensile-creep experiments were conducted at $370^{\circ} \mathrm{C}-440 \mathrm{MPa}$ and $455^{\circ} \mathrm{C}-315$ MPa. In each case the ratio of the applied creep stress to the YS was in the range of 0.6-0.75. The tensile-creep testing configuration was the same as that of the tensile testing, with the exception that pausing the experiment during image acquisition was not required due to the slow deformation rate during the creep tests. SE images were captured at regular intervals to 
characterize the surface deformation evolution. The temperature was maintained within $\pm 5 \mathrm{~K}$ of the target temperature for the duration of the experiments.

\subsection{Slip/Twin Trace Analysis Technique and Schmid Factor Calculation}

A slip/twin trace analysis was used to identify the active deformation systems [13]. Since nearly all of the microstructure consisted of the hexagonal phase, the slip/twin trace analysis was focused only on the hexagonal structure. The EBSD analysis provided the crystallographic orientation of each individual grain in the scanned area with reference to the sample/lab coordinate system given by the EBSD data in the form of three Euler angles $(\varphi 1, \Phi, \varphi 2)$. The orientation matrix $(g)$ between the crystal coordinate system and the sample/lab coordinate system was calculated by:

$g=\left[\begin{array}{ccc}\cos \varphi 2 & \sin \varphi 2 & 0 \\ -\sin \varphi 2 & \cos \varphi 2 & 0 \\ 0 & 0 & 1\end{array}\right]\left[\begin{array}{ccc}1 & 0 & 0 \\ 0 & \cos \Phi & \sin \Phi \\ 0 & -\sin \Phi & \cos \Phi\end{array}\right]\left[\begin{array}{ccc}\cos \varphi 1 & \sin \varphi 1 & 0 \\ -\sin \varphi 1 & \cos \varphi 1 & 0 \\ 0 & 0 & 1\end{array}\right]$

For a given observed slip trace, the slip plane and the slip direction can be expressed as (h k l) [u v w] in the crystal coordinate system using Miller indices. The transformation of the slip plane and the slip direction from the crystal coordinate system to the sample/lab coordinate system can be achieved using the rotation matrix (transpose of the orientation matrix) in equations (2) and

$$
n=g^{T} \cdot\left[\begin{array}{l}
h \\
k \\
l
\end{array}\right]
$$




$$
b=g^{T} \cdot\left[\begin{array}{l}
u \\
v \\
w
\end{array}\right]
$$

where $n$ and $b$ are the corresponding slip plane normal and slip direction of a given slip system in the sample/lab coordinate system. The superscript " $T$ " stands for the transpose of the matrix. The slip plane trace that can be observed was then calculated by the cross product of the slip plane normal $(n)$, expressed in the sample/lab coordinate, and the sample normal direction ([001]). A Matlab ${ }^{\mathrm{TM}}$ code [4] was used to calculate all the possible plane traces of the deformation systems for a given grain orientation. Identification of the experimentally-observed deformation systems in a given grain was accomplished by comparing the calculated plane traces with the slip plane traces observed in the SE images.

The global Schmid factor $(m)$ of each slip system in an individual grain can be estimated by resolving an assumed uniaxial stress $\sigma$ in the slip direction (Burgers vector direction $b$ ) on the slip plane (with normal n) (all expressed in the crystal coordinate system) by:

$$
m=n \bullet \sigma \bullet b^{T}
$$

There are three different slip directions on the basal plane (three $\langle a\rangle$ ) and pyramidal planes (one $\langle a\rangle$ and two $\langle c+a\rangle$ ), so the slip direction could not be unambiguously determined by the slip trace. The slip system with the highest Schmid factor was considered to be the active slip system when basal or pyramidal plane traces were observed. Also, when the deformation systems exhibited plane traces that could be attributed to multiple planes, the deformation system with the highest Schmid factor was chosen. Because the local stress tensor is not known in a particular location, all of the Schmid factor values were calculated based on a uniaxial global stress state. 
Figure 3(a) shows a SE image of a Ti-8Al-1Mo-1V RT temperature tensile-deformed microstructural patch with $\sim 5 \%$ local strain, along with a corresponding EBSD map (Figure 3(b)) (and inverse pole figure legend in Figure 3(c)) that includes identification numbers for the various grains. As outlined above, the slip traces for all of the 24 possible hexagonal slip systems for grain 275 were generated, as shown in Figure 3(d). The experimentally-observed slip traces, highlighted by the dotted line in Figure 3(a), were compared with the calculated slip traces to determine the active slip system in grain 275 . Figure 3(e) shows a tabulated slip-system chart showing the Schmid factors for all of the 24 slip systems, where the basal slip system number 3 ((0001) [11-20]) was determined to be the active slip system with a Schmid factor of 0.49. It is noted that the basal slip systems numbered 1 and 2 were also considered however their Schmid factors were 0.26 and 0.24 , respectively. This process was repeated for all of the grains that showed slip traces in the microstructural patches. It should be noted that twinning was not observed in any of the tensile or tensile-creep tests in this study.

\section{RESULTS}

\subsection{Microstructure}

Figure 4 shows a representative SE SEM image of the Ti-8Al-1Mo-1V microstructure. The $\beta$ phase (body centered cubic structure) was observed along the hexagonal $\alpha$-phase grain boundaries. The $\alpha$-phase consisted of $96 \pm 2 \%$ of the microstructure with an average $\alpha$-grain size of $15 \pm 3 \mu \mathrm{m}$. Figure 5 illustrates $\{0001\}$ and $\{10-10\}$ EBSD pole figure maps taken from a region measuring $30 \mathrm{~mm}$ by $20 \mathrm{~mm}$. These pole figures suggest that the alloy was not strongly textured. 


\subsection{Tensile Behavior}

The stress versus displacement curves for the four tensile tests are shown in Figure 6(a)-(d), with local strain values measured using microstructural features as fiducial markers indicated on the plots. The $25^{\circ} \mathrm{C}$ tensile test indicated a yield stress of approximately $910 \mathrm{MPa}$, which is consistent with prior work [19]. The yield stress decreased to approximately $650 \mathrm{MPa}$ at $260^{\circ} \mathrm{C}$, $510 \mathrm{MPa}$ at $455^{\circ} \mathrm{C}$, and $220 \mathrm{MPa}$ at $650^{\circ} \mathrm{C}$.

\subsection{Deformation Modes}

\subsection{1 $25^{\circ} \mathrm{C}(\mathrm{RT})$ Tension}

During the RT tensile deformation, approximately $92 \%$ of all the grains in the microstructural patches analyzed showed evidence of at least one slip trace mode. A few grains showed instances of more than one slip trace, indicating that more than one slip deformation mode was active in that grain. Prismatic slip was the most frequently observed slip mode. Figure 7(a) shows an SE image of the microstructure after $\sim 0.7 \%$ local strain, when the first instance of slip traces were observed, at a stress below the global yield stress. Figure 7(b) shows an SE image of the same area at $2.7 \%$ strain, which is well beyond the macroscopic yield strain. Many more slip traces were observed at the higher strain. By $3.7 \%$ strain, a strong majority of the grains exhibited slip traces, as indicated by the SE image in Figure 7(c). In general, the slip traces were straight, with very little evidence of cross-slip. In Figure 7(a) and 7(c), some of the traces are color coded for prismatic slip (red), basal slip (blue) and the associated Schmid factors are indicated next to the slip traces. The sample was strained in-situ to approximately 5\%, with a corresponding stress level of $\sim 1000 \mathrm{MPa}$, and was not taken to failure. No twinning was observed at any of the strain levels. This is consistent with previous observations of decreased twin activity observed for Ti-Al alloys having larger $\mathrm{Al}$ contents [2,12,21]. Figure 8 shows a 
histogram of the number of grains with a given slip mode (note, multiple slip lines for a give slip system in a given grain count 1 , two different slip line sets corresponding to two different slip systems of the same type in a given grain count 2) as a function of the Schmid factor, binned in 0.05 increments, after $3.7 \%$ strain. Prismatic slip accounted for approximately $70 \%$ of the total slip system activity, while basal, pyramidal $<\mathrm{c}+\mathrm{a}>$, and pyramidal $<\mathrm{a}>$ slip accounted for $21 \%$, $7 \%$, and $2 \%$ of the activity respectively. In general, grains with high Schmid factors exhibited higher slip frequencies. Nevertheless, some grains with low Schmid factors $(<0.2)$ also exhibited slip traces, presumably activated when the local neighborhood caused deviations from the uniaxial stress state.

\subsection{2 $260^{\circ} \mathrm{C}$ Tension}

During the $260^{\circ} \mathrm{C}$ tensile deformation, approximately $93 \%$ of the grains in the microstructural patches analyzed showed evidence of at least one slip trace, with a few grains showing more than one slip trace. As with the ambient temperature test, the first slip traces developed at stresses below the global yield stress.. At this elevated temperature, there were instances of wavy slip bands, suggesting some cross-slip had been activated. Straining was stopped at $13 \%$, prior to failure.

Figure 9 gives a histogram of the number of observed slip systems as a function of the Schmid factor for the $260^{\circ} \mathrm{C}$ deformed sample at a strain level of approximately $4.8 \%$. Again, prismatic slip was the most active deformation mode, but in this instance it only accounted for approximately $47 \%$ of the total slip system activity. Basal slip was much more active, accounting for nearly $35 \%$ of the total slip system activity. Pyramidal $<\mathrm{c}+\mathrm{a}>$ and $<\mathrm{a}>$ slip only contributed a small amount to the deformation, $11 \%$ and $7 \%$ respectively. While high Schmid factor systems dominated the deformation, the distribution shifted towards lower Schmid factors. 


\subsection{3 $455^{\circ} \mathrm{C}$ Tension}

During $455^{\circ} \mathrm{C}$ tensile deformation, approximately $94 \%$ of all the grains in the microstructural patches analyzed showed evidence of at least one slip trace mode, while a few grains also showed instances of more than one slip trace mode. The final strain level achieved was approximately $22 \%$ and the sample was not taken to failure. Figure 10(a) shows an SE image of the microstructure after a deformation of approximately $3.6 \%$ at a stress level of approximately 405MPa. Figure 10(b) shows an SE image of the microstructure at a strain level of 9.4\%, where more slip traces were observed. In addition, it is clear that significant topography has developed along some of the $\alpha$ boundaries. It is not clear if this is a result of slip in the $\beta$ or if boundary sliding mechanisms are activated. Figure 10(c) shows an SE image of the same area of the microstructure after $21.4 \%$ strain, which shows that cracks are beginning to develop at the $\alpha$ boundaries. Figure 11 shows the histogram of the number of grains with a given slip mode activation as a function of the Schmid factor at a strain level of 9.4\%. Basal slip was the dominant slip mode, accounting for $45 \%$ of the total slip system activity, with prismatic slip accounting for approximately $43 \%$. Pyramidal $\langle\mathrm{c}+\mathrm{a}\rangle$ and $\langle\mathrm{a}\rangle$ slip accounted for $2 \%$ and $10 \%$, respectively, of the total slip system activity. Similar to the lower temperature tests, the histogram also indicates that slip systems higher Schmid factors were more active.

\subsection{4 $650^{\circ} \mathrm{C}$ Tension}

No slip traces were observed during the $650^{\circ} \mathrm{C}$ tension test, although grain boundary relief and the formation of grain boundary ledges continued. This topography development was associated with cracking, with the cracks typically initiating from the triple point junctions or grain boundaries. With continued straining these boundary cracks were found to propagate into grain 
interiors. The sample failed after a strain of approximately $25 \%$, with a corresponding stress of $240 \mathrm{MPa}$. The deformed sample cross-section was metallographically polished to characterize the nature of the cracking. No evidence of internal cracking was observed, suggesting that the cracks observed were localized at the specimen surface.

\subsubsection{0 ${ }^{\circ} \mathrm{C}-440 \mathrm{MPa}$ Creep}

Compared to the tensile-deformed samples, a lower percentage of grains exhibited slip traces in the creep samples deformed to similar strain. Based on previously-measured tensile data [17], $440 \mathrm{MPa}$ represents approximately 0.75 of the yield strength at $370^{\circ} \mathrm{C}$.

After $9 \%$ strain, the $370^{\circ} \mathrm{C}-440 \mathrm{MPa}$ tensile creep sample displayed identifiable slip traces in only $21 \%$ of all the grains in the microstructural patches analyzed, compared to $>90 \%$ in the tensile experiments. Of the grains that did display slip traces, most only revealed one active slip mode, with only a few of the grains exhibiting more than one slip trace mode. Basal slip was very active, accounting for $84 \%$ of the slip modes observed, while prismatic slip was only rarely observed. Figure 12(a) shows an SE image of a microstructural patch at a strain level of approximately $5.7 \%$, showing that several grain boundary ledges formed. This observation, combined with the fact that only $21 \%$ of the grains exhibited slip traces, suggests that grain boundary sliding may have contributed significantly to the plastic strain. Figure 12(b) shows an SE image of the same microstructural patch after $8.6 \%$ strain. An increase in the number of slip traces was observed along with the development of more grain boundary ledges. At this strain, cracks began to develop, with some of the cracks moving in to the $\alpha$ grains. Figure 13 shows a histogram of the number of grains with identifiable slip lines associated with the various slip modes as a function of the Schmid factor. Basal slip was dominant, while pyramidal $<\mathrm{c}+\mathrm{a}>$ slip 
accounted for $10 \%$ of the total slip system activity. Prismatic slip and pyramidal <a> slip each accounted for remaining $3 \%$ of the observed slip trace modes. Similar to the tensile tests, this histogram suggests that slip systems with higher Schmid factors were more frequently activated, although one grain showed pyramidal $<\mathrm{c}+\mathrm{a}>$ slip activity with a Schmid factor $<0.2$.

Some of the cracks observed during this test propagated through the $\alpha$ grains, as seen in Figure 14. Trace analysis was used to determine the crack propagation planes and there was no tendency for the cracks to follow a particular plane. It is interesting to note that the grains that exhibited cracking did not exhibit slip traces, indicating that cracking was the preferred mode of deformation during creep of these grains.

\subsection{6 $455^{\circ} \mathrm{C}-315 \mathrm{MPa}$ Creep}

A stress level of $315 \mathrm{MPa}$ represents 0.6 of the yield strength at $455^{\circ} \mathrm{C}$ [17]. Similar to the lower temperature/higher stress creep test, less grains displayed slip traces at this creep condition compared to the tensile tested sample deformed to a similar strain level. However in this case, $72 \%$ of all the grains in the observed microstructural patch exhibited slip traces which is more than triple that for the lower temperature/higher stress creep test. Thus, higher temperature creep conditions appear to favor a larger percentage of grains exhibiting slip traces. In the grains that exhibited at least one slip trace mode, basal slip activity was again the most frequently observed slip mode, where basal slip accounted for $58 \%$ of observed slip modes. However a higher frequency of prismatic slip activity was observed, 37\%, than in the higher stress/lower temperature creep experiment. This, along with the lack of cracking observed in this sample, suggests that the test condition (i.e. stress and temperature) could have a sensitive effect on the relative slip mode activity and cracking behavior, with higher temperatures permitting more 
homogeneous deformation and thus less localization leading to cracking. The final strain level reached was approximately 5\% and the sample was not taken to failure. Figure 15(a) shows an SE image which represents the microstructural patch of the sample creep deformed at $455^{\circ} \mathrm{C}$ $315 \mathrm{MPa}$ at a strain level $\sim 3 \%$. Grain boundary ledges were evident. Figure 15 (b) shows a SE image of the same microstructural patch area at a strain level of approximately $4 \%$. The number of observed slip traces increased with increasing strain. Figure 16 shows a histogram showing the distribution of the active slip systems as a function of the Schmid factor during the $455^{\circ} \mathrm{C}$ $315 \mathrm{MPa}$ creep test after $4 \%$ strain. Similar to the tensile tests, this histogram also suggested that slip systems with higher Schmid factors were more frequently activated.

\section{DISCUSSION}

The distribution of the slip modes was strongly dependent on the test condition. In the tensile tests, dislocation slip was prevalent. Prismatic slip activity was prevalent during RT tensile testing. With increased temperature, basal slip activity became more active relative to prismatic slip. At $455^{\circ} \mathrm{C}$ an almost equal number of basal and prismatic slip traces were observed. Compared to the tensile tests, the creep samples exhibited a lower number of grains which exhibited slip traces at similar strain levels. This is consistent with previous observations

of $\mathrm{Ti}-5 \mathrm{Al}-2.5 \mathrm{Sn}(\mathrm{wt} . \%)$ [12], where the applied creep stress was between 0.6-0.8 of the YS, similar to the stresses used in the present study. Because dislocation slip is generally favored at higher stress levels [22], one would expect fewer slip traces for the creep-deformed samples compared with the tensile-deformed samples. Basal slip was the dominant slip activity observed in both creep tests, although there was a large difference in the relative amount of the prismatic slip activity observed between the two tests, indicating that both stress and temperature play an important role in determining the relative slip system activities in Ti alloys [12]. The propensity 
for prismatic slip increased for the sample creep tested at higher temperature. This is consistent with $\mathrm{Li}$ et al. [12] who has also showed that with increased temperature during creep deformation for Ti-5Al-2.5Sn(wt.\%), prismatic slip becomes more dominant. The creep tested samples exhibited more grain boundary relief and a larger amount of grain boundary ledges than the tensile deformed samples, indicating that grain boundary sliding is an active deformation mode at elevated temperature during the creep tests.

Transgranular cracks formed during the $370^{\circ} \mathrm{C}-440 \mathrm{MPa}$ creep test. The lack of cracking in the higher temperature/lower stress creep condition implies that there is a stress threshold below which cracking is less likely. For Ti-8Al-1Mo-1V containing a Widmanstatten $\alpha-\beta$ microstructure, Wojcik et al. [23] observed the propagation of fatigue cracks during RT tensiontension fatigue along the basal planes. The cracks were observed to propagate along the $<11$ 20> directions. The maximum applied stress was around $300 \mathrm{MPa}$, which is lower than the stress applied during the creep test for the current study. This highlights the susceptibility of cracking for Ti-8Al-1Mo-1V during fatigue and creep loadings well below the global yield stress of the alloy.

Twinning has been observed in CP-Ti during the temperature range of $25-455^{\circ} \mathrm{C}$ [4]. It has also been reported that an increased $\mathrm{Al}$ content and increased temperature results in decreased twinning activity [2,4]. In agreement, a comparison of the twinning activity for four commercial Ti alloys (CP Ti, Ti-5Al-2.5Sn, Ti-3Al-2.5V and Ti-6Al-4V) showed that generally twinning was less favored for alloys containing more $\mathrm{Al}$ content [4]. In the current work, no twins were observed and this observations agrees with previous work indicating higher Al content inhibits twinning in Ti alloys. 


\subsection{Comparison of the Deformation Behavior with CP Ti, Ti-5Al-2.5Sn, and Ti-6Al-4V}

\section{Tension}

Dislocation slip was the primary tensile deformation mechanism observed in the tensile tests for each of the materials. However, the relative activity of the different deformation systems changed as a function of alloy composition and temperature. Prismatic slip was commonly observed in each material. However, basal slip was more active in Ti-8Al-1Mo-1V, Ti-5Al-2.5Sn, and Ti-6Al-4V compared with CP Ti. Extensive basal slip has also been observed in Ti-6Al-4V [11] and Ti-6Al [24]. These observations, along with the current work, are consistent with prior work that showed that as the $c / a$ ratio increases with increasing $\mathrm{Al}$ content [6], the basal plane becomes more closely packed and thus more favorable for slip, while the prismatic planes become less closely packed and less favorable for slip. Increases in Al content also result in a decrease in the stacking fault energy on the basal planes. Guo et al. [25] found that the stacking fault energy decreases from $0.31 \mathrm{~J} / \mathrm{m}^{2}$ for CP Ti to $0.082 \mathrm{~J} / \mathrm{m}^{2}$ for Ti-5.3Al (wt.\%). Zaefferer [3] found that the increase in $\mathrm{Al}$ content results in a decrease in the stacking fault energy on the basal planes, and as a consequence, dislocation movement is increasingly restricted to the basal planes when increased $\mathrm{Al}$ contents are presented. For these reasons, Ti8Al-1Mo-1V is expected to show the enhanced basal slip activity with respect to prismatic slip activity compared to $\mathrm{CP} \mathrm{Ti}$.

Alloying with Al suppresses twin formation. Twins only accounted for approximately $1 \%$ of the deformation systems in Ti-5Al-2.5Sn deformed at 296K $[4,12,13,26]$. For Ti-6Al-4V deformed at both $25^{\circ} \mathrm{C}$ and $455^{\circ} \mathrm{C}$, twinning accounted for no more than $4 \%$ of the deformation systems [27]. For Ti-8Al-1Mo-1V no twinning was observed. However, twinning accounted for over 9\% of the deformation systems in CP Ti deformed at $25^{\circ} \mathrm{C}$ and $455^{\circ} \mathrm{C}$ [26]. The observation 
of less deformation twinning in polycrystalline Ti-5Al-2.5Sn, Ti-6Al-4V, and the currently evaluated Ti-8Al-1Mo-1V is therefore consistent with the observations of Williams et al. [2], who showed that twinning decreased with the addition of $\mathrm{Al}$ in the $\alpha$ phase.

\section{Creep}

This section compares the tensile-creep deformation behavior of the currently examined Ti-8Al-1Mo-1V to that for Ti-6Al-4V [27], CP Ti [4,26], and Ti-5Al-2.5Sn [4,26]. During the elevated-temperature tensile-creep tests, the relative activity of dislocation slip and grain boundary sliding varied from material to material. During the $455^{\circ} \mathrm{C}-250 \mathrm{MPa}$ creep deformation of Ti-5Al-2.5Sn [4,26], $455^{\circ} \mathrm{C}-315 \mathrm{MPa}$ deformation of Ti-8Al-1Mo- $1 \mathrm{~V}$, and $455^{\circ} \mathrm{C}-310 \mathrm{MPa}$ creep deformation of Ti-6Al-4V [27], grain boundary sliding appeared to be the primary deformation mechanism rather than dislocation slip. Although the ratio of the applied creep stress to the YS was similar in CP Ti (0.73), Ti-5Al-2.5Sn (0.76), Ti-8Al-1Mo-1V (0.6), and Ti6Al-4V (0.74), dislocation slip, rather than grain boundary siding, was the dominant deformation mechanism in $\mathrm{CP} \mathrm{Ti}$ creep. It has been reported that finer grain sizes enhance grain boundary sliding [28-30]. Thus, the deformation mechanism difference between these materials during creep may depend more strongly on the grain size difference. CP Ti exhibited the largest grain size $(\mathrm{d}=140.4 \pm 25.7 \mu \mathrm{m})$ followed by Ti-5Al-2.5Sn $(\mathrm{d}=39.5 \pm 10.0 \mu \mathrm{m})$ then Ti-8Al-1Mo- $1 \mathrm{~V}(\mathrm{~d}=$ $15 \pm 3 \mu \mathrm{m})$, and $6.4 \pm 4.4 \mu \mathrm{m}$ for Ti- $6 \mathrm{Al}-4 \mathrm{~V}$.

The percentage of grains exhibiting slip traces out of the total number of grains and the preferred slip systems when slip occurred also varied from material to material. During the $455^{\circ} \mathrm{C}-45 \mathrm{MPa}$ creep test of $\mathrm{CP} \mathrm{Ti}[4,26], \sim 97 \%$ of the total grains exhibited slip traces and prismatic slip dominated (64\%). Thus, dislocation slip was the dominant deformation 
mechanism in the tensile-creep test of $\mathrm{CP} \mathrm{Ti}$, and when slip occurred, prismatic slip was preferred. In contrast, no slip traces were observed during the $455^{\circ} \mathrm{C}-310 \mathrm{MPa}$ creep test of Ti6Al-4V [27], and grain boundary sliding was clearly a dominant deformation mechanism to accommodate plastic deformation. In the $455^{\circ} \mathrm{C}-250 \mathrm{MPa}$ creep test of Ti-5Al-2.5Sn $[4,26]$, only $\sim 10 \%$ of the total grains exhibited slip traces, where $78 \%$ of deformation systems were basal slip and $16 \%$ of the deformation systems were prismatic slip. Similarly, in the $455^{\circ} \mathrm{C}-315 \mathrm{MPa}$ creep test of Ti-8Al-1Mo-1V, $84 \%$ of deformation systems were basal slip and prismatic slip only comprised 3\%. Therefore, for Ti-5Al-2.5Sn and Ti-8Al-1Mo-1V, grain boundary sliding was the primary deformation mechanism and when slip occurred, basal slip was the preferred system.

\section{SUMMARY AND CONCLUSIONS}

The deformation behavior of Ti-8Al-1Mo-1V with a weak crystallographic texture was studied using in-situ tensile and tensile-creep experiments performed inside a SEM. The distribution of the slip deformation was measured for tensile test performed at $25^{\circ} \mathrm{C}, 260^{\circ} \mathrm{C}, 455^{\circ} \mathrm{C}$, and $650^{\circ} \mathrm{C}$, as well as for creep experiments performed at $370^{\circ} \mathrm{C}$ and $455^{\circ} \mathrm{C}$ at applied stress values between $0.6-0.75$ of the YS. No twinning was observed in any of the tests. During tension deformation, the relative amount of basal slip activity increased with respect to prismatic slip activity with increased temperature, such that at $455^{\circ} \mathrm{C}$, prism and basal slip was nearly equal. During creep deformation, a lower amount of slip activity was observed and a greater amount of grain boundary ledge formation was observed, indicating that grain boundary sliding is an active deformation mechanism during the creep experiments. During creep, basal slip was more active than prismatic slip and some transgranular cracking was observed. The deformation behavior of Ti-8Al-1Mo-1V was compared to that for other near- $\alpha$ and $\alpha+\beta$ Ti alloys. 


\section{Acknowledgments}

This research was supported by the United States Department of Energy, Office of Basic Energy Science through grant No. DE-FG02-10ER46637. 


\section{BIBLIOGRAPHY}

[1] Yoo M.H., Slip, twinning and fracture in hexagonal close-packed metals, Metallurgical Transactions A, Vol. 12, Issue 12, pp 409-418, 1981.

[2] Williams J.C., Baggerly R.G., and Paton N.E., Deformation behavior of HCP Ti-Al alloy single crystals, Metallurgical and Materials Transaction A, Vol. 33, No. 13, pp. 837-850, 2002.

[3] Zaefferer S., A study of active deformation systems in titanium alloys: dependence on alloy composition and correlation with deformation texture, Materials Science and Engineering A, Vol. 344, No. 1-2, pp. 20-30, 2003.

[4] Li H., Analysis of the deformation behavior of the hexagonal close-packed alpha phase in titanium and titanium Alloys, Doctoral Dissertation, 2013.

[5] Gong J. and Wikinson A.J., Anisotropy in the plastic flow properties of single-crystal $\alpha$ titanium determined from micro-cantilever beams, Acta Materialia, Vol. 57, No. 19, pp. 56935705, 2009.

[6] Teer D.G. and Salem F.B., The formation of low friction wear-resistant surfaces on titanium by ion plating, Thin Solid Films, Vol. 45, No. 3, pp. 583-589, 1977.

[7] Mises R. von, Mechanik der Festen Korper im plastisch deformablen, Math-Phys., Vol. 1, pp. 582-592, 1913.

[8] Paton N.E. and Backofen W.A., Plastic deformation of titanium at elevated temperatures, Metallurgical Transactions A, Vol. 1, Issue 10, pp 2839-2847, 1970.

[9] Chan K.S., A micromechanical analysis of the yielding behavior of individual widmanstätten colonies of an $\alpha+\beta$ titanium alloy, Metallurgical and Materials Transactions A, Vol. 35, No. 11, pp. 3409-3422, 2004.

[10] Bieler T.R and Semiatin S.L., The origins of heterogeneous deformation during primary hot working of Ti-6Al-4V, International Journal of Plasticity, Vol. 18, No. 9, pp. 1165-1189, 2002.

[11] Bridier F., Villechaise P., and Mendez J., Analysis of the different slip systems activated by tension in a $\alpha / \beta$ titanium alloy in relation with local crystallographic orientation, Acta Materialia, Vol. 53, No. 3, pp. 555-567, 2005.

[12] Li H., Boehlert C.J., Bieler T.R., and Crimp M.A., Analysis of slip activity and heterogeneous deformation in tension and tension-creep of Ti-5Al-2.5Sn (wt\%) using in-situ SEM experiments, Philosophical Magazine, Vol. 92, No. 23, pp. 2923-2946, 2012.

[13] Li H., Mason D.E., Bieler T.R., Boehlert C.J., and Crimp M.A., Methodology for estimating the critical resolved shear stress ratios of $\alpha$-phase Ti using EBSD-based trace analysis, Acta Materialia, Vol. 61, pp 7555-7567, 2013. 
[14] Teer D.G. and Salem F.B., The formation of low friction wear-resistant surfaces on titanium by ion plating, Thin Solid Films, Vol. 45, No. 3, pp. 583-589, 1977.

[15] Salem A.A., Kalidindi S.R., and Semiatin S.L., Strain hardening due to deformation twinning in $\alpha$-titanium: Constitutive relations and crystal-plasticity modeling, Acta Materialia, Vol. 53, No. 12, pp. 3495-3502, 2005.

[16] Balasubramanian S. and Anand L., Plasticity of initially textured hexagonal polycrystals at high homologous temperatures: application to titanium, Acta Materialia, Vol. 50, No. 1, pp. 133148, 2002.

[17] Jenkins W.D. and Williard W.A., Creep rupture properties of Ti-8Al-1Mo-1V alloy, Journal of Research of the National Bureau of Standards-C. Engineering and Instrumentation, Vol. 72C, No. 2, 1968.

[18] http://en.wikipedia.org/wiki/Atomic_radii_of_the_elements_(data_page).

[19] Boyer R., Welsch G., and Collings E.W., editors. Materials Properties Handbook: Titanium Alloys. Materials Park, OH: ASM International, 1994.

[20] ASTM, E112-96 standard test methods for determining average grain size, 2004.

[21] Chan K.S., Wojcik C.C., and Koss D.A., Deformation of an alloy with a lamellar microstructure: experimental behavior of individual widmanstatten colonies of an $\alpha-\beta$ titanium alloy, Metallurgical Transactions A, Vol. 12A, pp-1899, Nov. 1981.

[22] Lüthy H., White R.A., and Sherby O.D., Grain boundary sliding and deformation mechanism maps, Materials Science and Engineering, Vol. 39, Issue 2, pp 211-216, August 1979.

[23] Wojcik C.C., Chan K.S., and Koss D.A., Stage I fatigue crack propagation in $\alpha$-titanium alloy, Acta Metall., Vol. 36, No.5, pp. 1261-1270, 1988.

[24] Neeraj T., Hou D.H., Daehn G.S., and Mills M.J., 2000, Phenomenological and microstructural analysis of room temperature creep in titanium alloys, Acta Materialia, Vol. 48, No. 6, pp. 1225-1238.

[25] Guo Z., Miodownik A.P., Saunders N., and Schillé J-Ph, 2006, Influence of stacking-fault energy on high temperature creep of alpha titanium alloys, Scripta Materialia, Vol. 54, No. 12, pp. $2175-2178$.

[26] Li H., Mason D.E., Yang Y., Bieler T.R., Crimp M.A., and Boehlert C.J., 2013, Comparison of the deformation behaviour of commercially pure titanium and $\mathrm{Ti}-5 \mathrm{Al}-2.5 \mathrm{Sn}$ (wt.\%) at 296 and 728 K, Philosophical Magazine, Vol. 93, No. 21, pp. 2875-2895. 
[27] Li, H., Boehlert, C.J., Bieler, T.R. and Crimp, M.J., Examination of the Distribution of the Tensile Deformation Systems in Tension and Tension-Creep of Ti-6Al-4V(wt.\%) at 296K and 728K, Philosophical Magazine, 2015, Vol. 95 no. 7 (2015) 691-729. (http://dx.doi.org/10.1080/14786435.2014.1001459)

[28] Chokshi A.H., 1990, An evaluation of the grain-boundary sliding contribution to creep deformation in polycrystalline alumina, Journal of Materials Science, Vol. 25, No. 7, pp. 32213228 .

[29] Langdon T.G., 1970, Grain boundary sliding as a deformation mechanism during creep, Philosophical Magazine, Vol. 22, No. 178, pp. 689-700.

[30] Zelin M.G., Yang H.S., Valiev R.Z., and Mukherjee A.K., 1992, Interaction of hightemperature deformation mechanisms, Metallurgical Transactions A, Vol. 23, No. 11, pp. 31353140 . 


\section{LIST OF FIGURES}

Figure 1. A schematic geometry of the test specimen used in the tensile and tensile-creep experiments. The dimensions are in millimeters.

Figure 2. An image showing the in-situ testing setup in the Tescan Mira3 SEM chamber.

Figure 3. Example of slip trace analysis performed on a RT tensile deformed microstructure with $\sim 5 \%$ strain in grain 275 . The dashed white line in (a) indicates the experimentally-observed slip band direction. The tensile direction EBSD IPF map (b) provides the orientation for grain 275 (provide Euler angles). The EBSD color code (c) and coordinate system, where $\mathrm{X}$ is the RD and $\mathrm{Y}$ is the TD (tensile direction). The calculated slip trace directions (d) for the 24 hexagonal slip systems and the unit cell, where only basal slip systems 1, 2, and 3 matched the experimentally-observed slip band direction, marked by the green line. Slip systems with Schmid factors greater than 0.2 are tabulated (e), indicating that basal slip system 3 (0001) [1120] in bold was the active slip system with a Schmid factor of 0.49. This Burgers vector is indicated on the unit cell (d) by the light blue line starting from the solid circle, and the slip plane is shaded, and the calculated slip trace is indicated by the blue dashed line going through the origin.

Figure 4. SE SEM images showing the microstructure of Ti-8Al-1Mo-1V.

Figure 5. $\{0001\}$ and $\{10-10\} E B S D$ pole figure maps from the transverse section (ND $\|$ bar axis) of a region measuring $30 \mathrm{~mm}$ by $20 \mathrm{~mm}$.

Figure 6. Stress vs. displacement plots for samples tested at (a) $25^{\circ} \mathrm{C}$, (b) $260^{\circ} \mathrm{C}$, (c) $455^{\circ} \mathrm{C}$ and (d) $650^{\circ} \mathrm{C}$. Note that the sample represented in (d) was the only sample that was taken to failure. The stress drops indicate stress relaxation that occurred when the tests were interrupted for capturing the SE SEM images. The local strain values are also indicated on the curve.

Figure 7. Sequential SE SEM images for the RT tensile-tested specimen: (a) $820 \mathrm{MPa}(\sim 0.7 \%$ strain), when the first slip bands (prismatic slip with a Schmid factor of 0.48) were observed, (b) $920 \mathrm{MPa}$ ( 2.7 strain) and (c) $950 \mathrm{MPa}(\sim 3.7 \%$ strain). The EBSD orientation map of the sample before the test is provided in (d). In (a) and (c), some of the traces are color coded for prismatic slip (red), basal slip (green) and the associated Schmid factor values are indicated next to the slip traces.

Figure 8. A histogram of the Schmid factor distribution of basal, prismatic, pyramidal $<a>$, and pyramidal $\langle\mathrm{c}+\mathrm{a}\rangle$ slip modes for the RT tensile-tested sample deformed to $\sim 3.7 \%$ strain. The numbers in parenthesis indicated the number of grains which exhibited slip traces for that particular deformation mode.

Figure 9. A histogram of the Schmid factor distribution of basal, prismatic, pyramidal $<\mathrm{a}\rangle$, and pyramidal $\langle\mathrm{c}+\mathrm{a}\rangle$ slip modes for the $260^{\circ} \mathrm{C}$ tension-tested sample deformed to $\sim 7.4 \%$ strain. The numbers in parenthesis indicated the number of grains which exhibited slip traces for that particular deformation mode. 
Figure 10. Sequential SE SEM images for the $455^{\circ} \mathrm{C}$ tensile-tested specimen: (a) $405 \mathrm{MPa}$ ( $3.6 \%$ strain), (b) $448 \mathrm{MPa}(\sim 9.4$ strain) and (c) $458 \mathrm{MPa}(\sim 21.4 \%$ strain). The EBSD orientation map of the sample before the test is provided in (d). In (b), slip traces are color coded for prismatic slip (red) and basal slip (green), and associated Schmid factors are indicated next to the slip traces.

Figure 11. A histogram of the Schmid factor distribution of basal, prismatic, pyramidal <a>, and pyramidal $\langle\mathrm{c}+\mathrm{a}\rangle$ slip modes for the $455^{\circ} \mathrm{C}$ tension-tested sample deformed to $\sim 9.4 \%$ strain. The numbers in parenthesis indicated the number of grains which exhibited slip traces for that particular deformation mode.

Figure 12. Sequential SE SEM images for the $370^{\circ} \mathrm{C}-440 \mathrm{MPa}$ tensile-creep tested specimen: (a) $\sim 5.7 \%$ strain, (b) $\sim 8.6$ strain. The EBSD orientation map of the sample before the test is provided in (c). In (b), slip traces are color coded for pyramidal slip (yellow), basal slip (green), and associated Schmid factors are indicated next to the slip traces.

Figure 13. A histogram of the Schmid factor distribution of basal, prismatic, pyramidal $<a>$, and pyramidal $\langle\mathrm{c}+\mathrm{a}\rangle$ slip modes for the $370^{\circ} \mathrm{C}-440 \mathrm{MPa}$ tension-creep sample deformed to $\sim 8.6 \%$ strain. The numbers in parenthesis indicated the number of grains which exhibited slip traces for that particular deformation mode.

Figure 14. (a) A low-magnification SE SEM images for the $370^{\circ} \mathrm{C}-440 \mathrm{MPa}$ tensile-creep tested specimen showing cracking ( $9 \%$ strain), where the cracks are numbered 1-7. (b) A highermagnification image of the crack labeled " 1 ".

Figure 15. Sequential SE SEM images for the $455^{\circ} \mathrm{C}-315 \mathrm{MPa}$ tensile-creep tested specimen: (a) $\sim 3 \%$ strain, (b) $\sim 4 \%$ strain. The EBSD orientation map of the sample before the test is provided in (c). In (b), slip traces are color coded for prismatic slip (red), basal slip (green), and associated Schmid factors are indicated next to the slip traces.

Figure 16. A histogram of the Schmid factor distribution of basal, prismatic, pyramidal <a>, and pyramidal $<\mathrm{c}+\mathrm{a}>$ slip modes for the $455^{\circ} \mathrm{C}-315 \mathrm{MPa}$ tension-creep sample deformed to $\sim 4 \%$ strain. The numbers in parenthesis indicated the number of grains which exhibited slip traces for that particular deformation mode. 
Figures

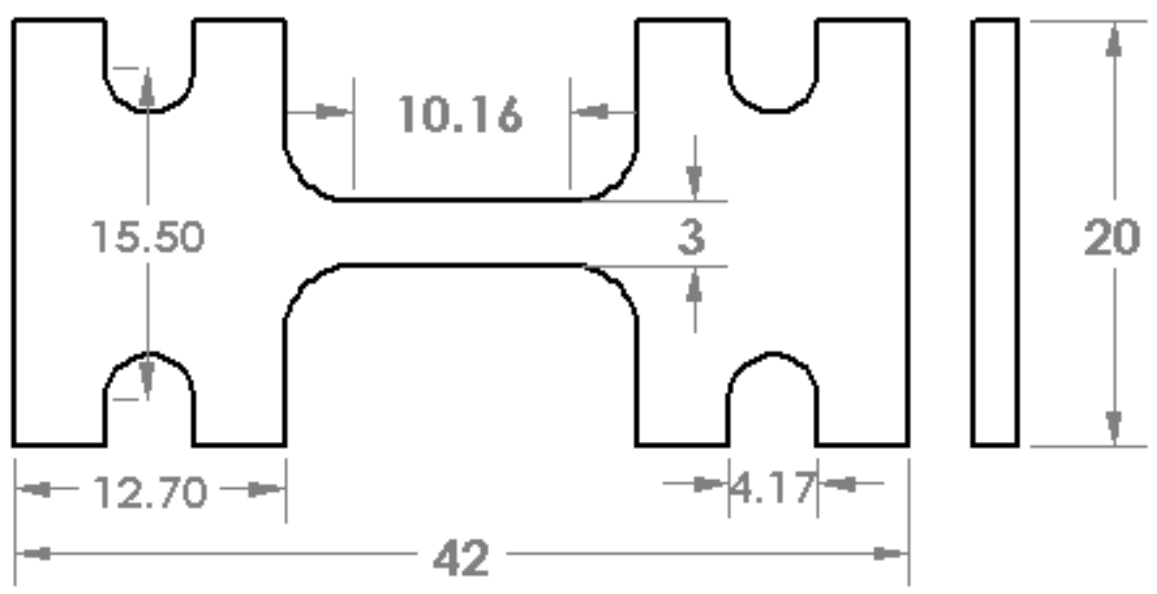

Figure 1. A schematic geometry of the test specimen used in the tensile and tensile-creep experiments. The dimensions are in millimeters. 


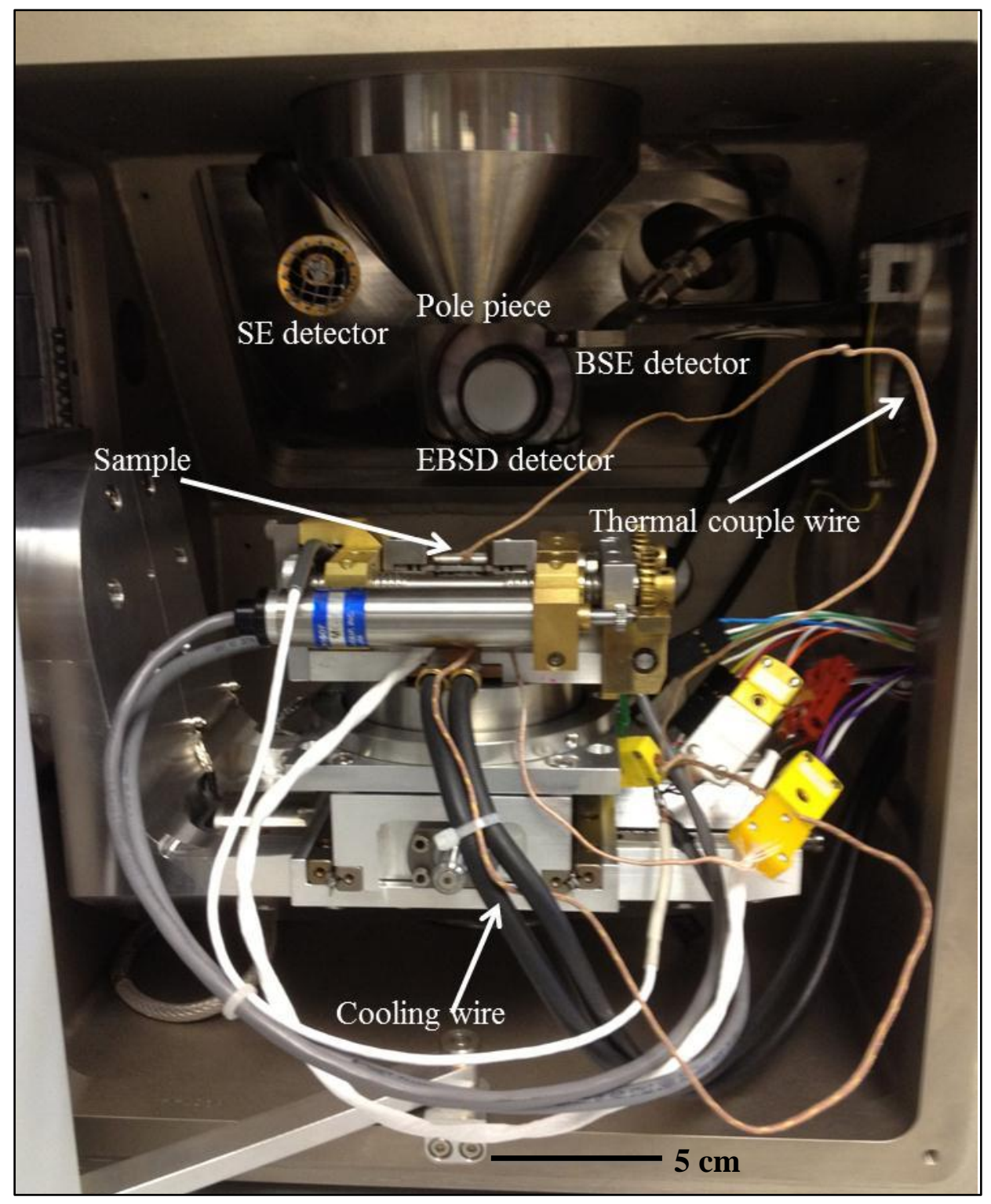

Figure 2. An image showing the in-situ testing setup in the Tescan Mira3 SEM chamber. 


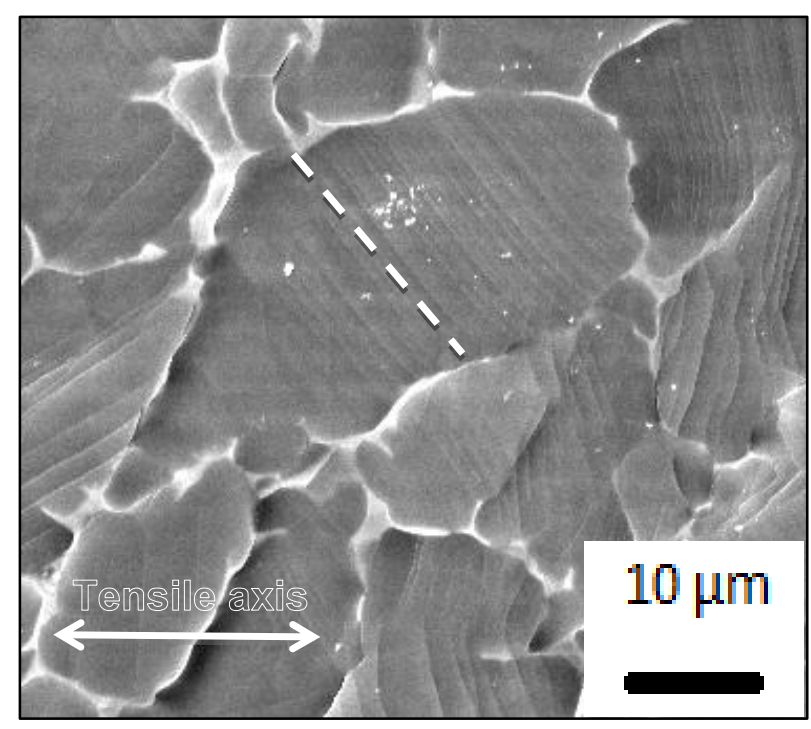

(a)

(c)

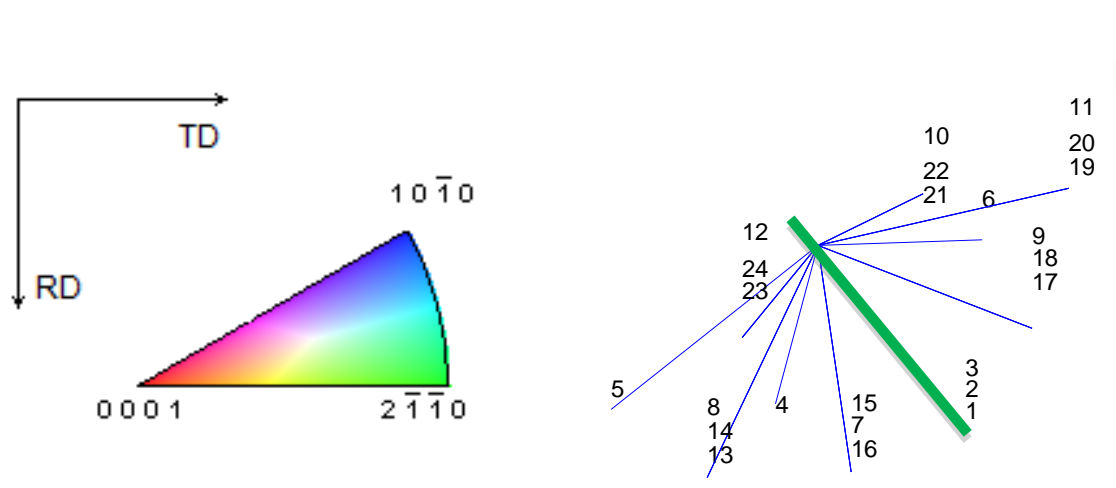

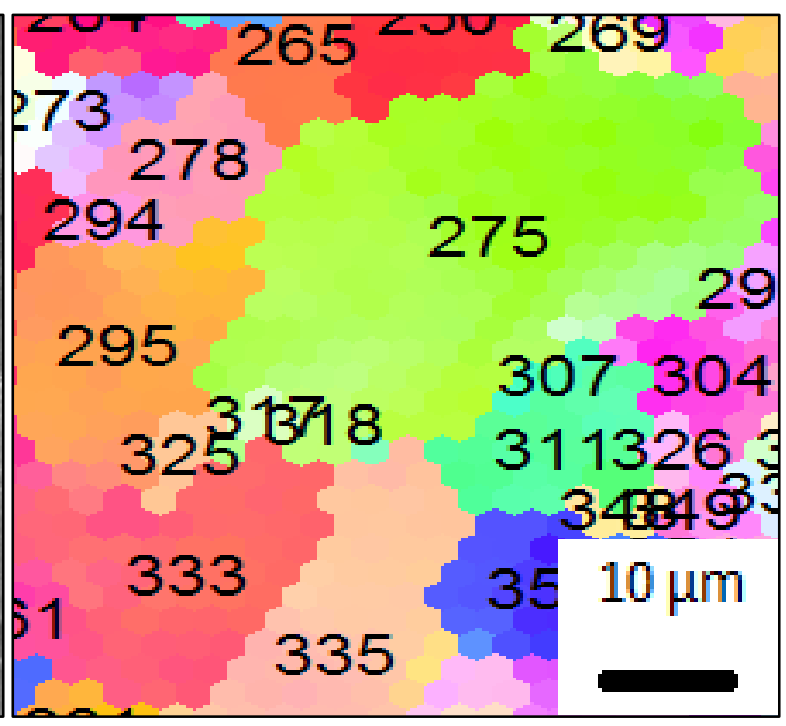

(b)

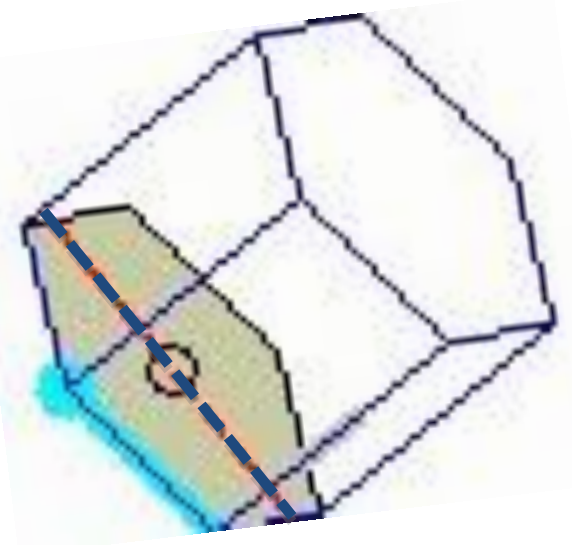

(d)

Figure 3. Example of slip trace analysis performed on a RT tensile deformed microstructure with $\sim 5 \%$ strain in grain 275 . The dashed white line in (a) indicates the experimentally-observed slip band direction. The tensile direction EBSD IPF map (b) provides the orientation for grain 275 (provide Euler angles). The EBSD color code (c) and coordinate system, where $\mathrm{X}$ is the RD and $\mathrm{Y}$ is the TD (tensile direction). The calculated slip trace directions (d) for the 24 hexagonal slip systems and the unit cell, where only basal slip systems 1,2, and 3 matched the experimentallyobserved slip band direction, marked by the green line. Slip systems with Schmid factors greater than 0.2 are tabulated (e), indicating that basal slip system 3 (0001) [11-20] in bold was the active slip system with a Schmid factor of 0.49. This Burgers vector is indicated on the unit cell (d) by the light blue line starting from the solid circle, and the slip plane is shaded, and the calculated slip trace is indicated by the blue dashed line going through the origin. 
Slip system Slip system type

1 Basal

2 Basal

3 Basal

4 Prismatic

5 Prismatic

$7 \quad$ Pyramidal $<\mathrm{a}\rangle$

$8 \quad$ Pyramidal $\langle a\rangle$

$9 \quad$ Pyramidal $\langle a\rangle$

12 Pyramidal $<\mathrm{a}>$

13 Pyramidal $\langle\mathrm{c}+\mathrm{a}\rangle$

16 Pyramidal $\langle\mathrm{c}+\mathrm{a}\rangle$

18 Pyramidal $\langle\mathrm{c}+\mathrm{a}\rangle$

20 Pyramidal $\langle\mathrm{c}+\mathrm{a}\rangle$

23 Pyramidal $<\mathrm{c}+\mathrm{a}>$
Slip system

(0001) [2-1-10]

(0001) [-12-10]

(0001) [11-20]

(01-10) [2-1-10]

(10-10) [-12-10]

(01-11) [2-1-10]

(10-11) [-12-10]

$(-1101)[-1-120]$

(1-101) [-1-120]

(10-11) [2-1-1-3]

$(-1101)$ [-12-1-3]

$(-1101)$ [-211-3]

$(-1011)$ [-1-12-3]

(1-101) [1-21-3]

(e)
Schmid factor

0.26

0.24

0.49

0.23

0.21

0.32

0.30

0.23

0.25

0.35

0.36

0.25

0.21

0.28 


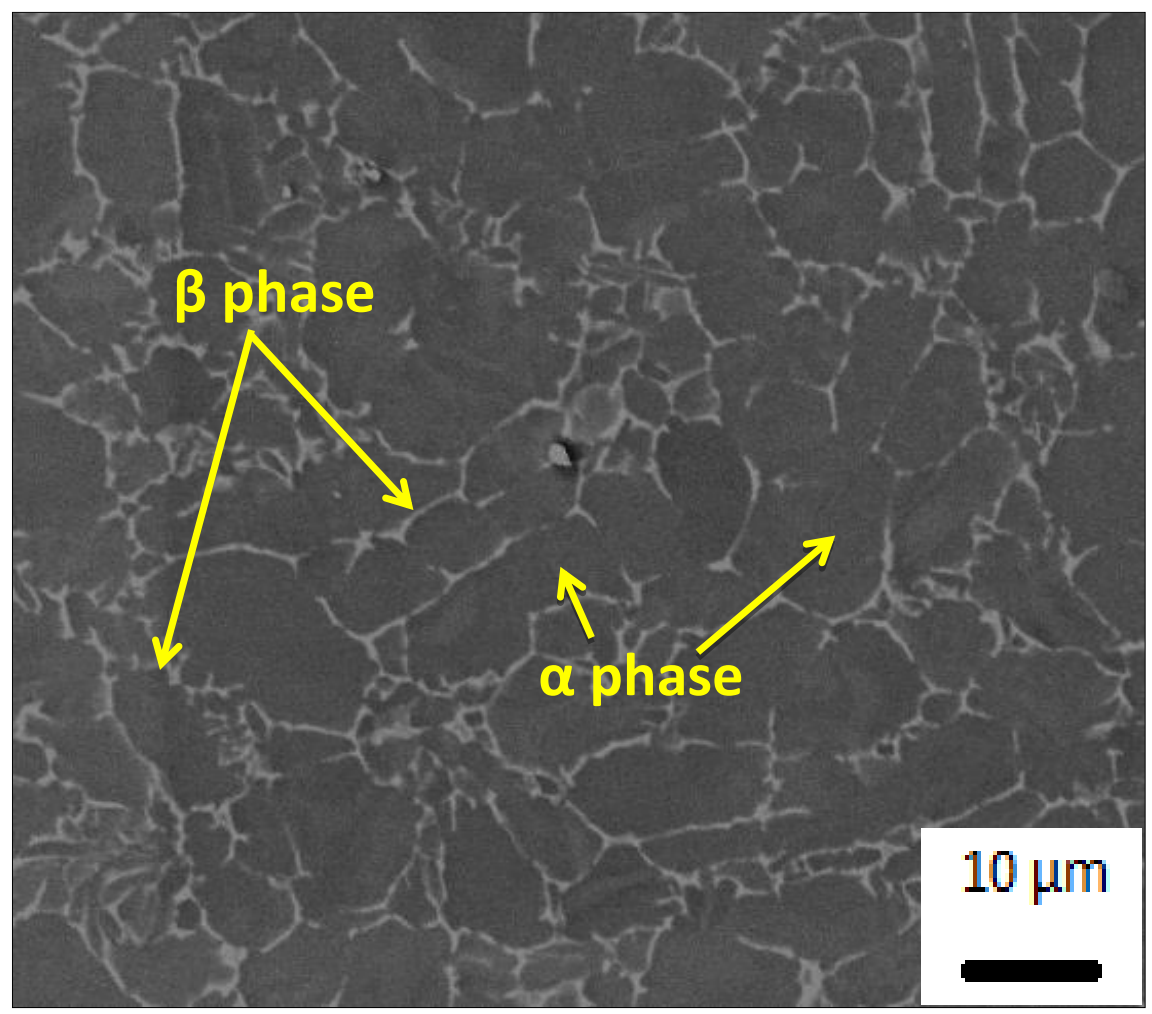

Figure 4. SE SEM images showing the microstructure of Ti-8Al-1Mo-1V. 

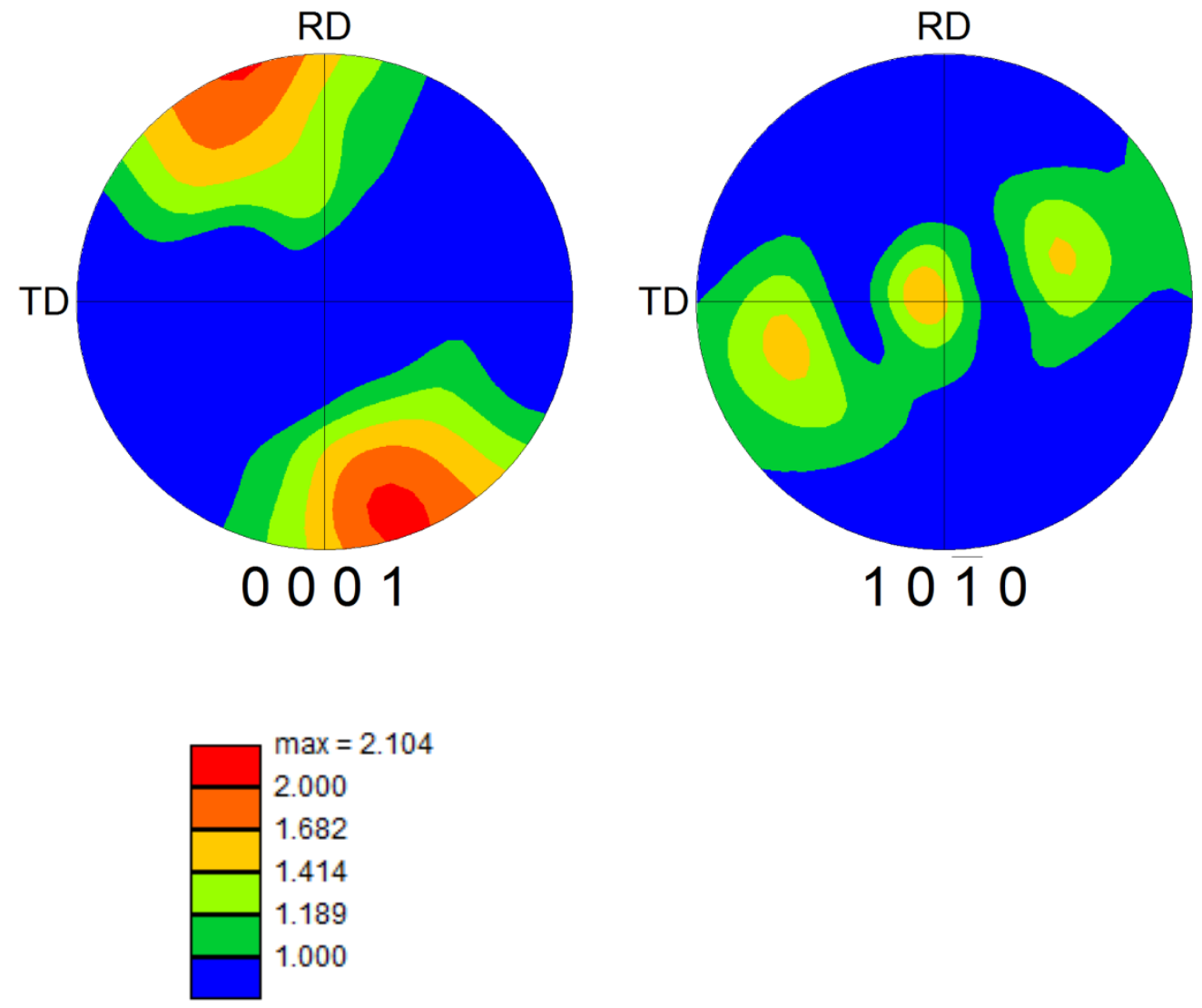

Figure 5. $\{0001\}$ and $\{10-10\}$ EBSD pole figure maps from the transverse section (ND $\|$ bar axis) of a region measuring $30 \mathrm{~mm}$ by $20 \mathrm{~mm}$. 


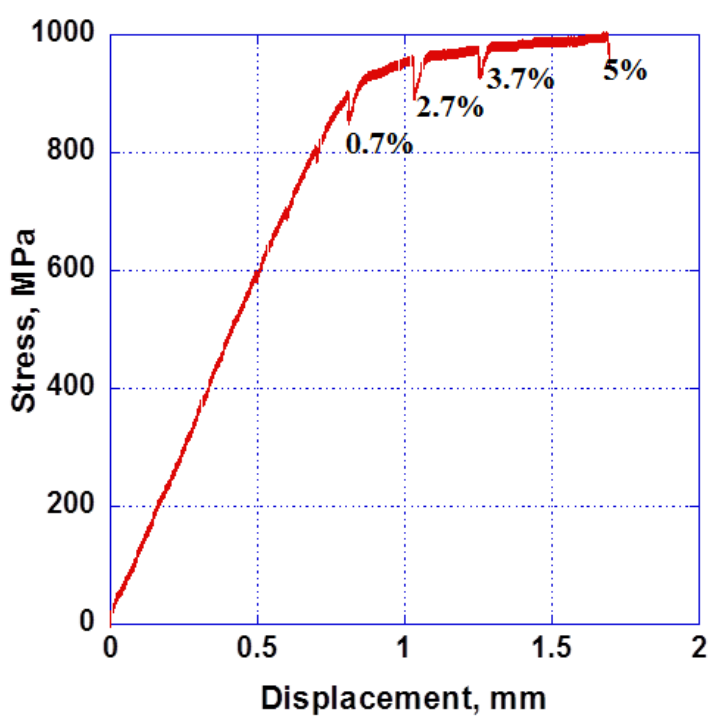

(a)

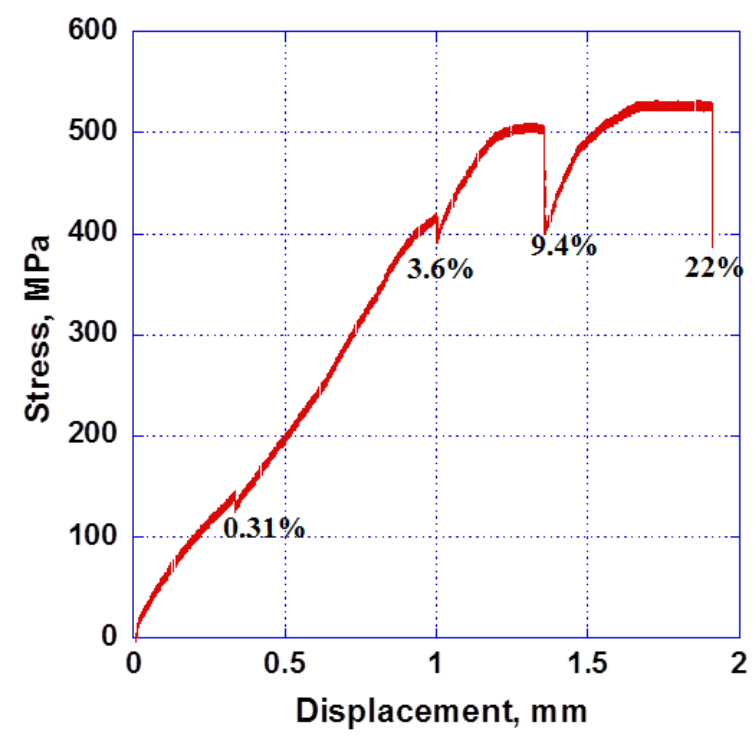

(c)

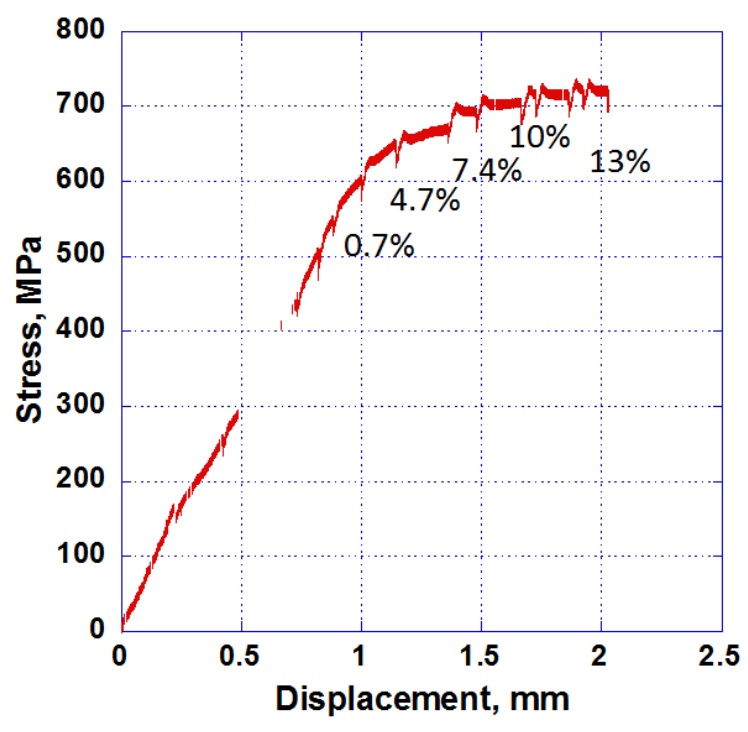

(b)

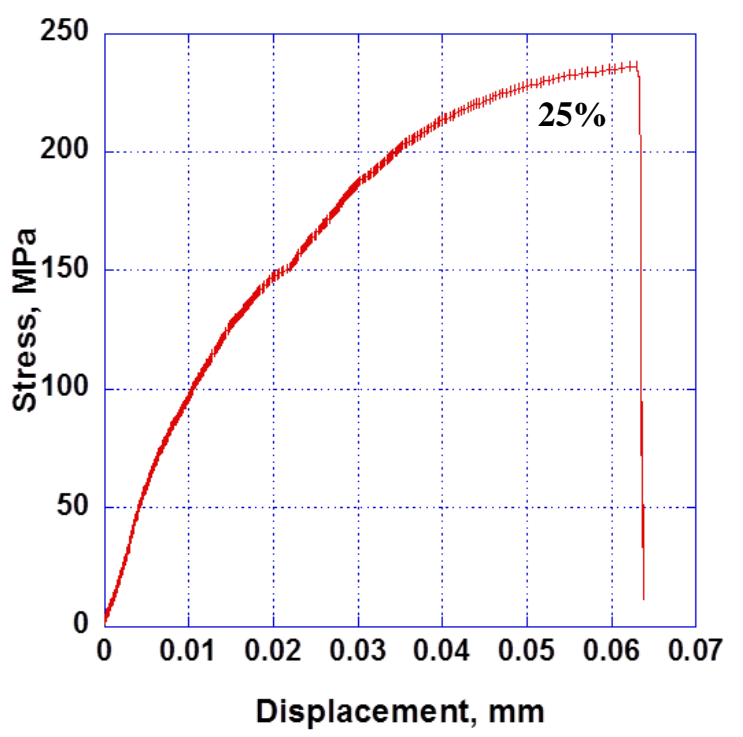

(d)

Figure 6. Stress vs. displacement plots for samples tested at (a) $25^{\circ} \mathrm{C}$, (b) $260^{\circ} \mathrm{C}$, (c) $455^{\circ} \mathrm{C}$ and (d) $650^{\circ} \mathrm{C}$. Note that the sample represented in (d) was the only sample that was taken to failure. The stress drops indicate stress relaxation that occurred when the tests were interrupted for capturing the SE SEM images. The local strain values are also indicated on the curve. 
(a)

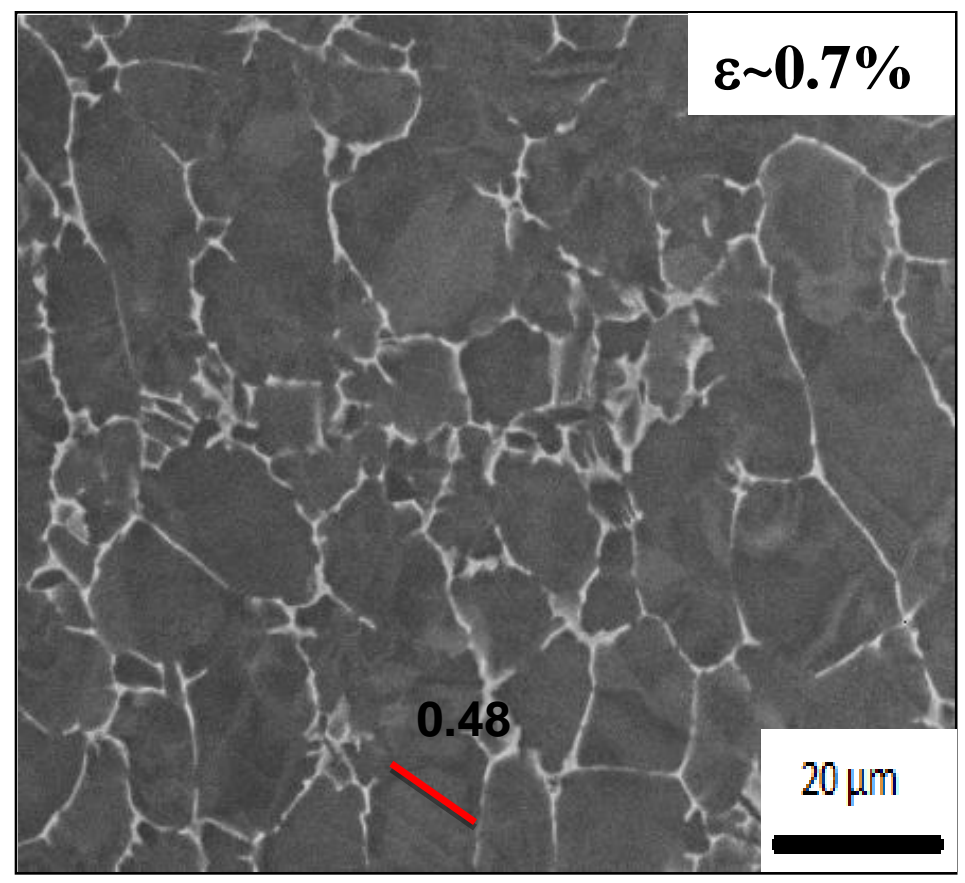

(b)

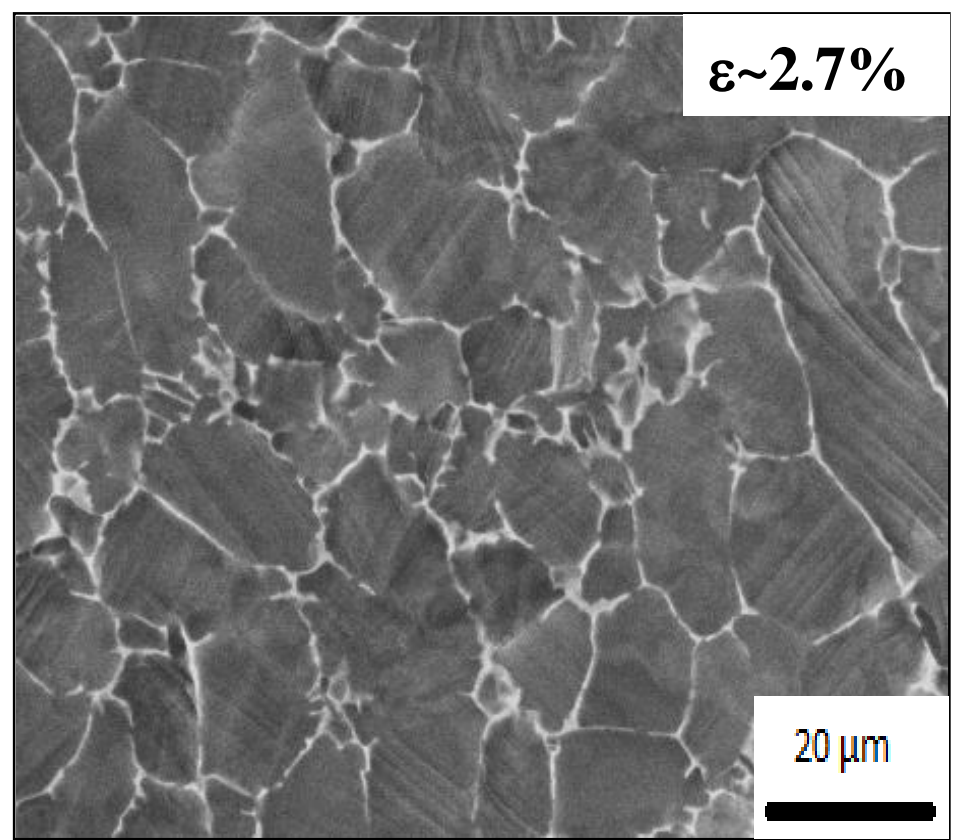

Tensile Direction

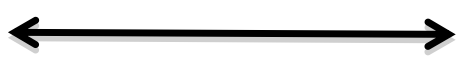


(c)

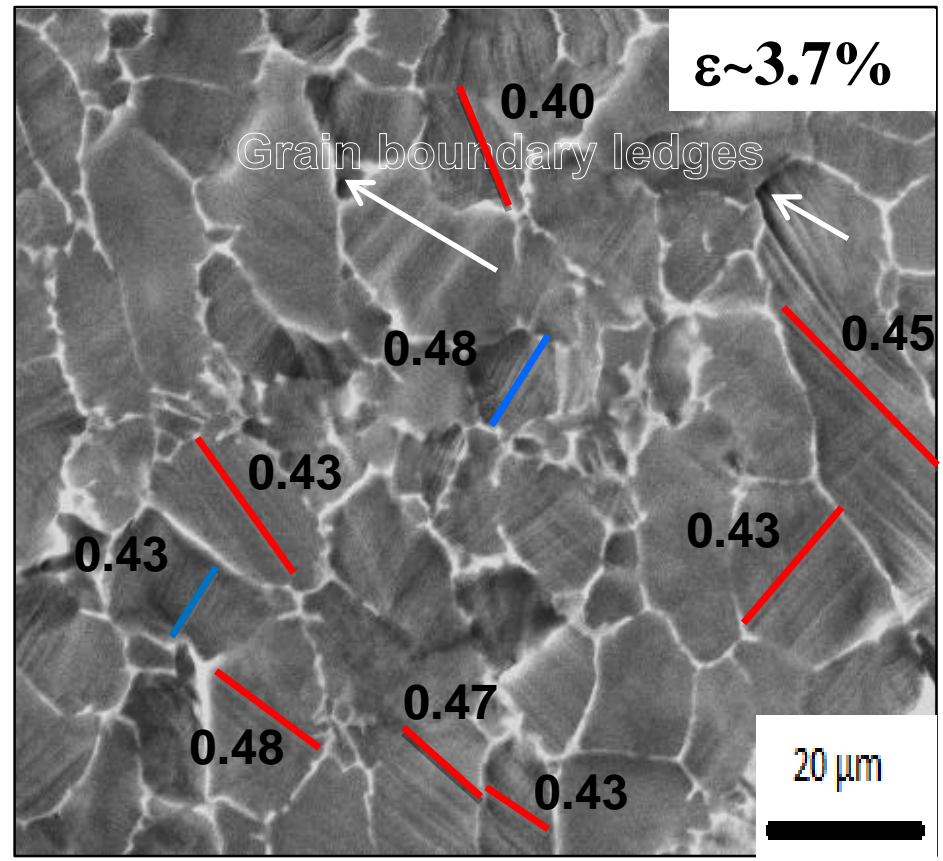

d)

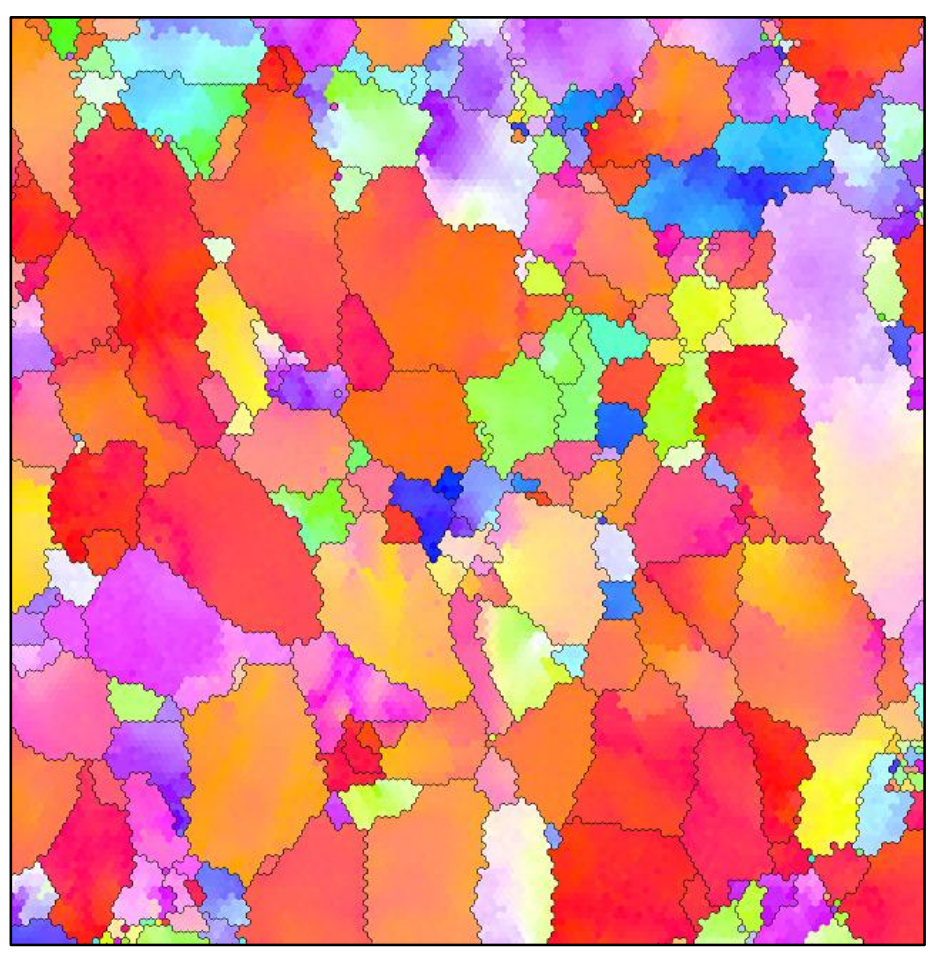




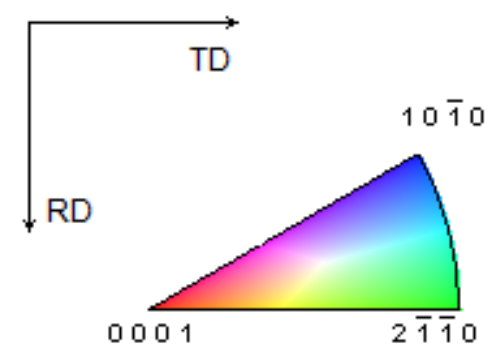

Figure 7. Sequential SE SEM images for the RT tensile-tested specimen: (a) $820 \mathrm{MPa}(\sim 0.7 \%$ strain), when the first slip bands (prismatic slip with a Schmid factor of 0.48) were observed, (b) $920 \mathrm{MPa}(\sim 2.7$ strain) and (c) $950 \mathrm{MPa}(\sim 3.7 \%$ strain). The EBSD orientation map of the sample before the test is provided in (d). In (a) and (c), some of the traces are color coded for prismatic slip (red), basal slip (blue) and the associated Schmid factors are indicated next to the slip traces. 


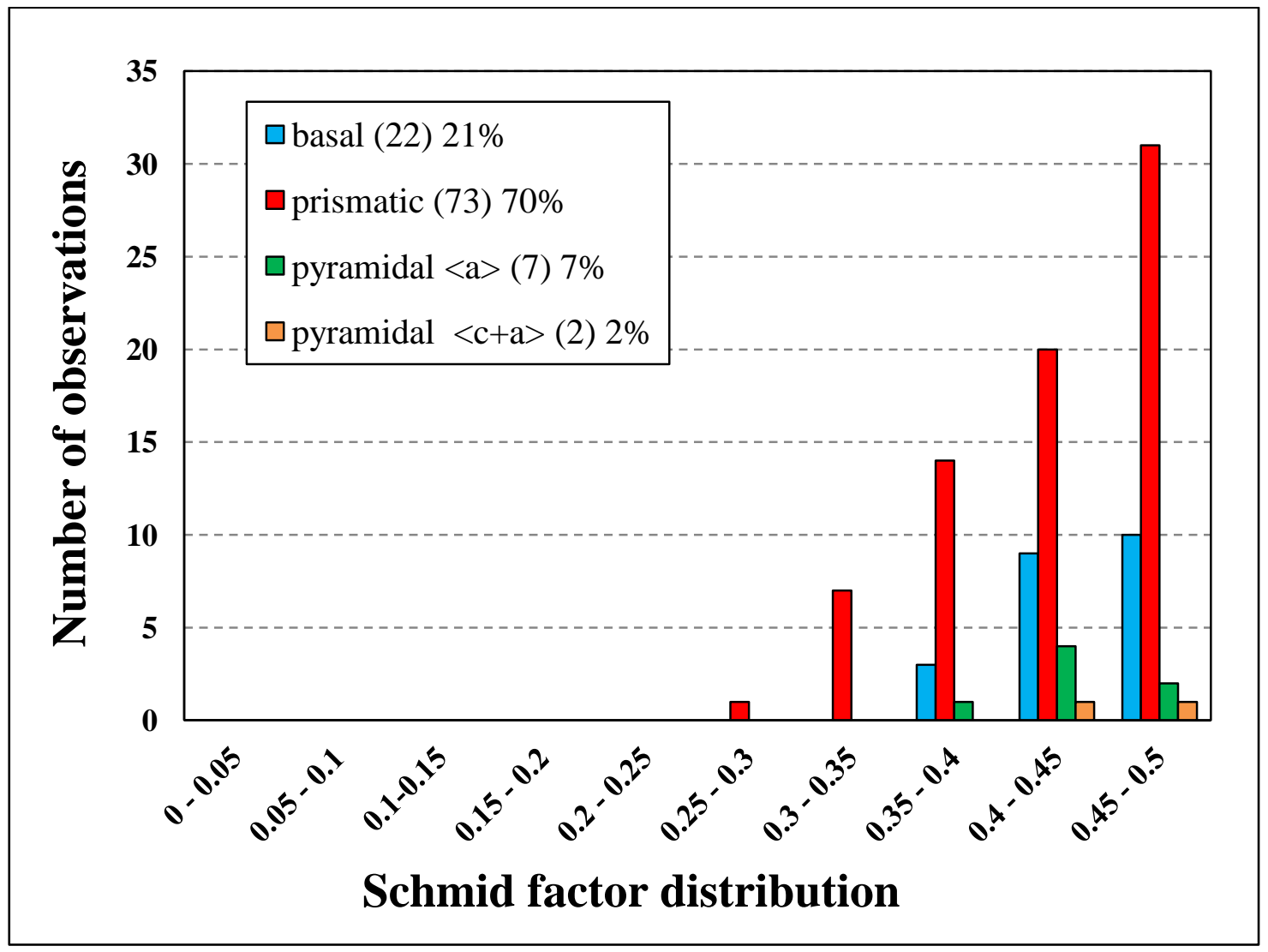

Figure 8. A histogram of the Schmid factor distribution of basal, prismatic, pyramidal $\langle a\rangle$, and pyramidal $\langle\mathrm{c}+\mathrm{a}\rangle$ slip modes for the RT tensile-tested sample deformed to $\sim 3.7 \%$ strain. The numbers in parenthesis indicated the number of grains which exhibited slip traces for that particular deformation mode. 


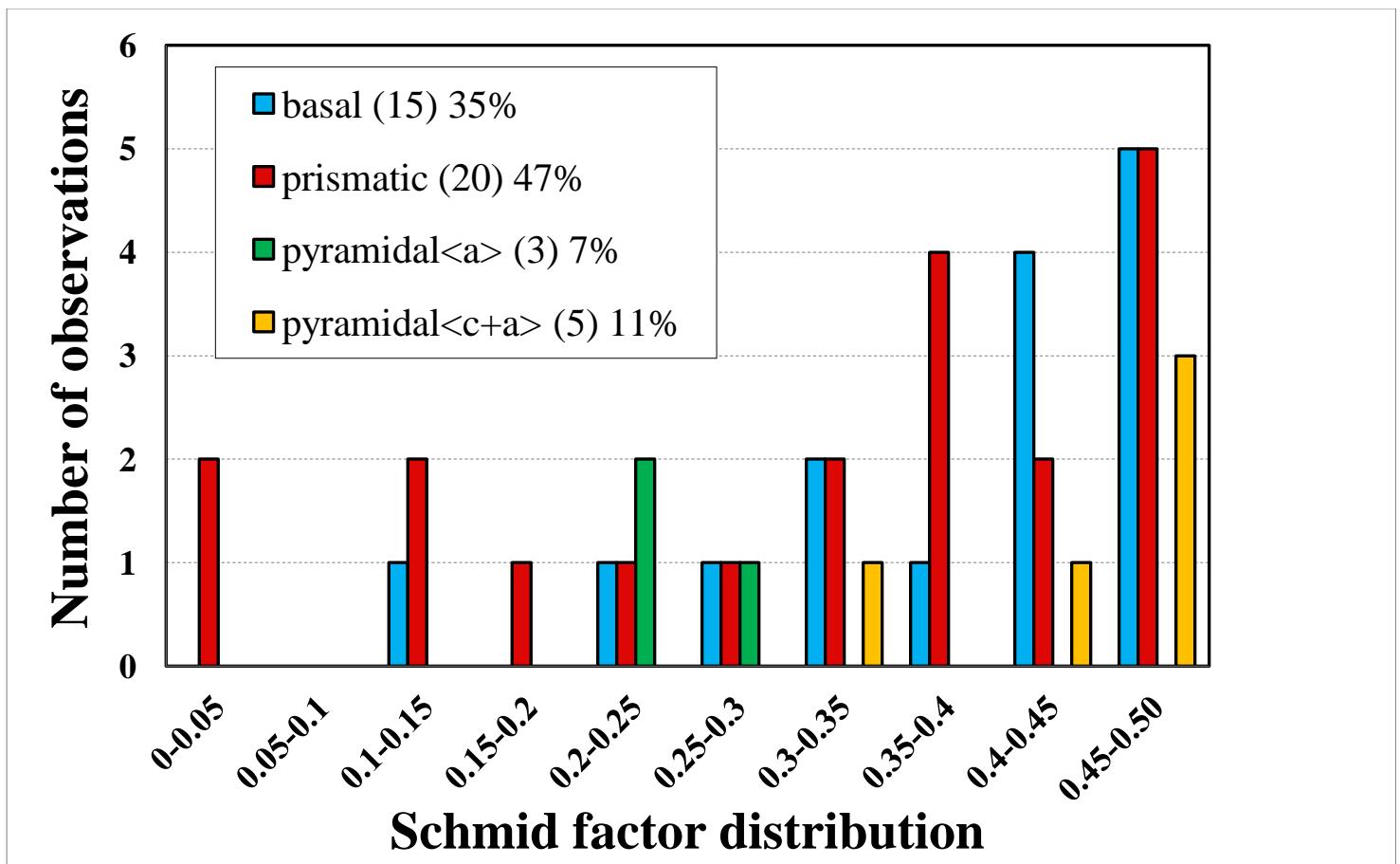

Figure 9. A histogram of the Schmid factor distribution of basal, prismatic, pyramidal <a>, and pyramidal $<\mathrm{c}+\mathrm{a}>\operatorname{slip}$ modes for the $260^{\circ} \mathrm{C}$ tension-tested sample deformed to $\sim 7.4 \%$ strain. The numbers in parenthesis indicated the number of grains which exhibited slip traces for that particular deformation mode. 
(a)

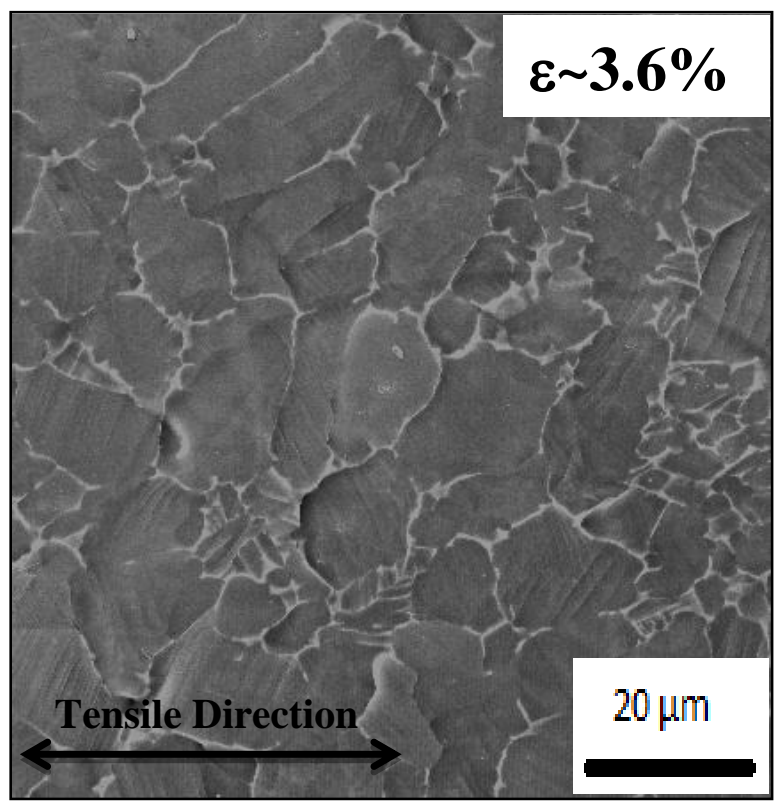

(b)

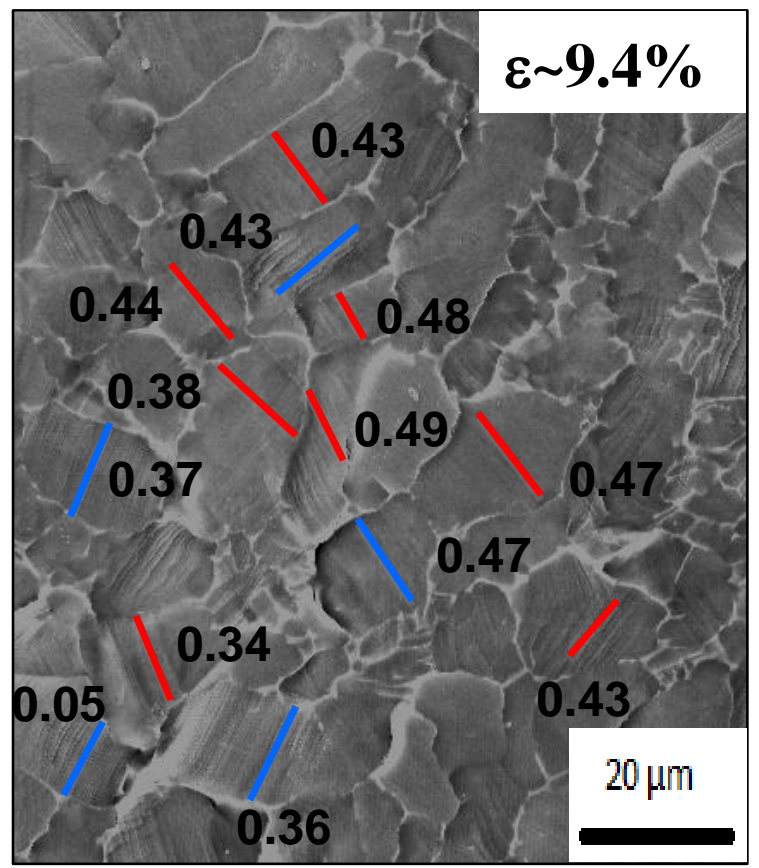


(c)

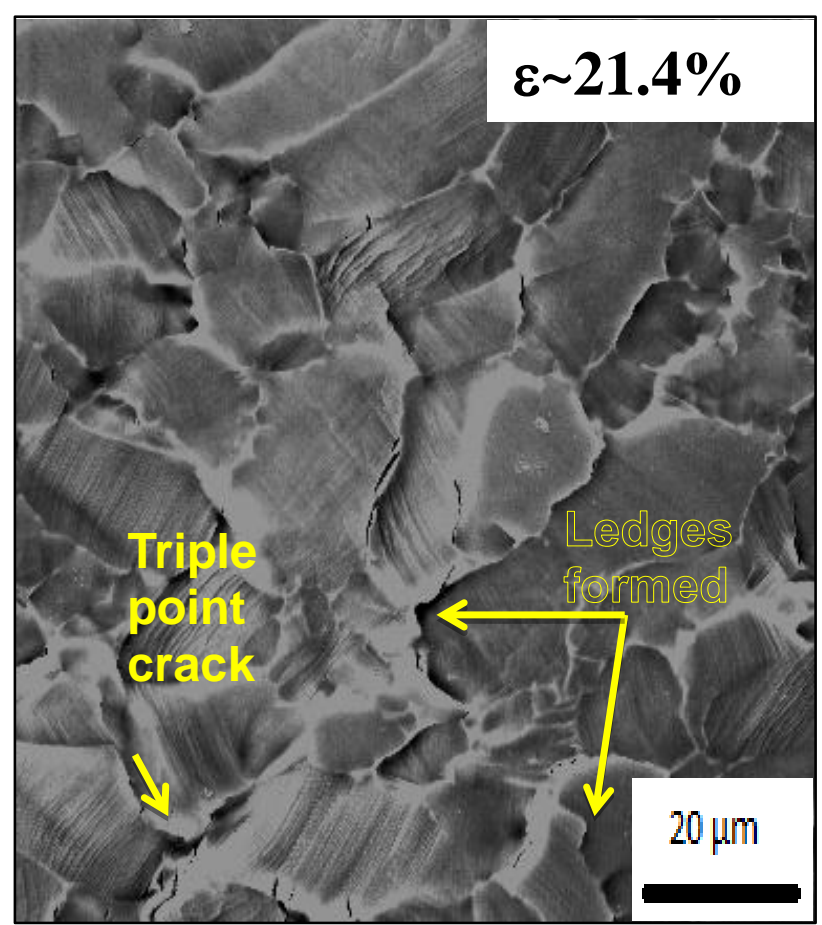

d)

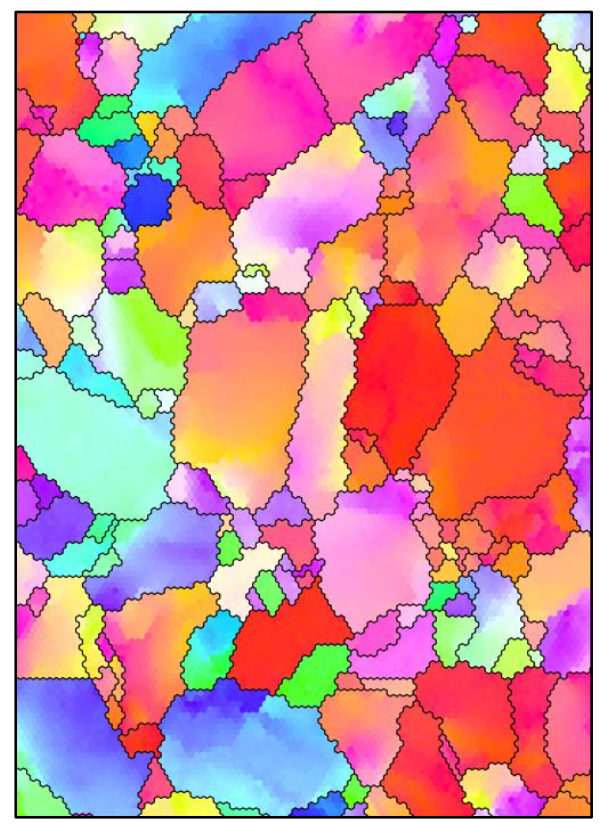




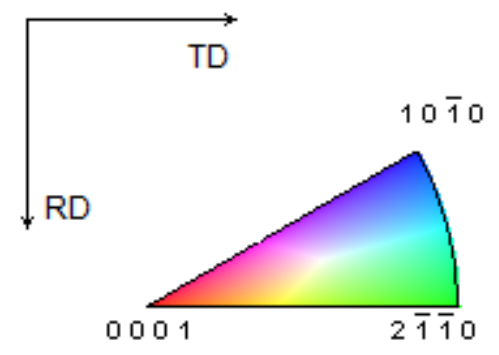

Figure 10. Sequential SE images for the $455^{\circ} \mathrm{C}$ tensile-tested specimen: (a) $405 \mathrm{MPa}(\sim 3.6 \%$ strain), (b) $448 \mathrm{MPa}$ ( $~ 9.4$ strain) and (c) $458 \mathrm{MPa}(\sim 21.4 \%$ strain). The EBSD orientation map of the sample before the test is provided in (d). In (b), slip traces are color coded for prismatic slip (red) and basal slip (blue), and associated Schmid factors are indicated next to the slip traces. 


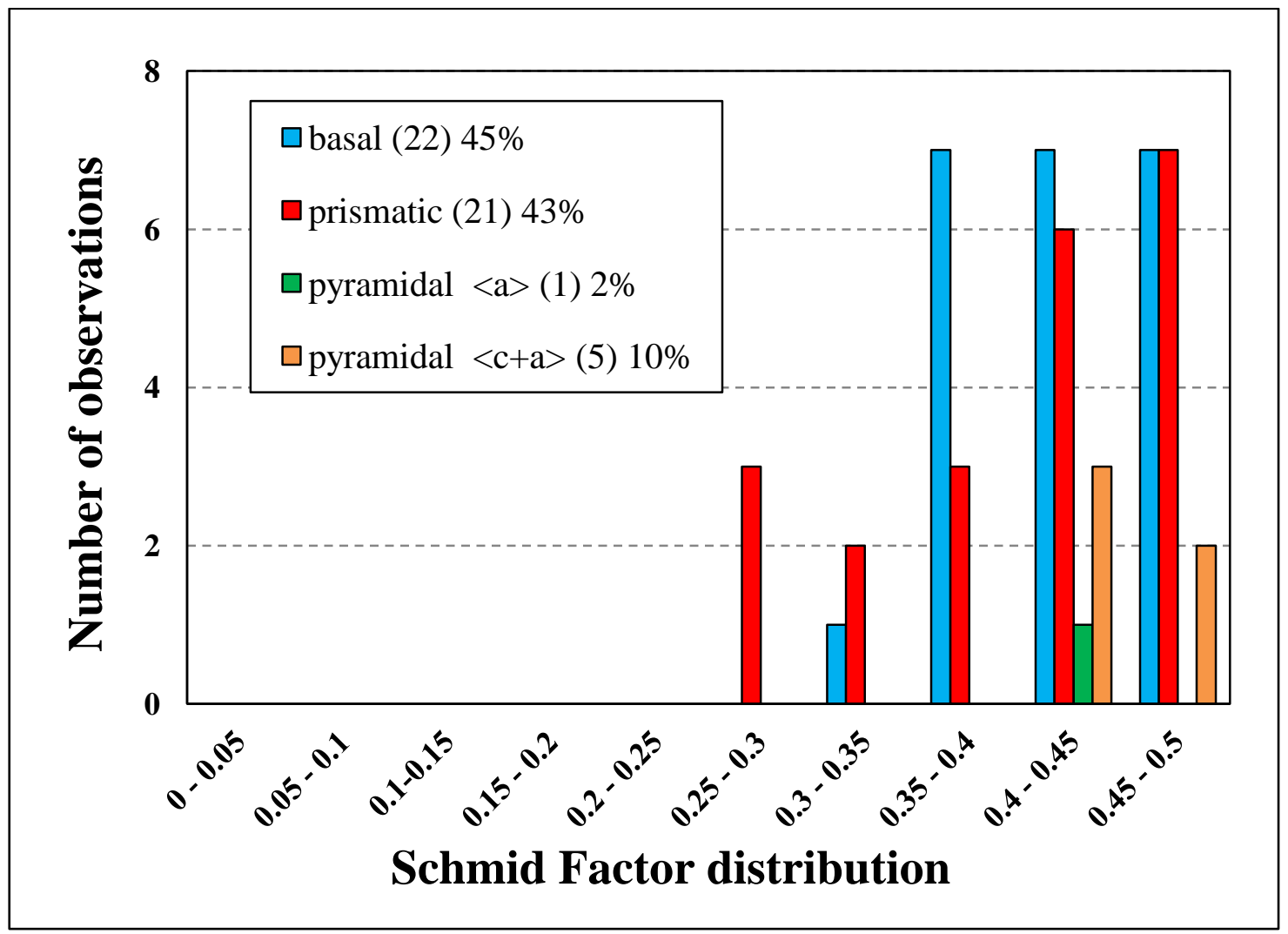

Figure 11. A histogram of the Schmid factor distribution of basal, prismatic, pyramidal $\langle\mathrm{a}\rangle$, and pyramidal $\langle\mathrm{c}+\mathrm{a}\rangle$ slip modes for the $455^{\circ} \mathrm{C}$ tension-tested sample deformed to $\sim 9.4 \%$ strain. The numbers in parenthesis indicated the number of grains which exhibited slip traces for that particular deformation mode. 
(a)

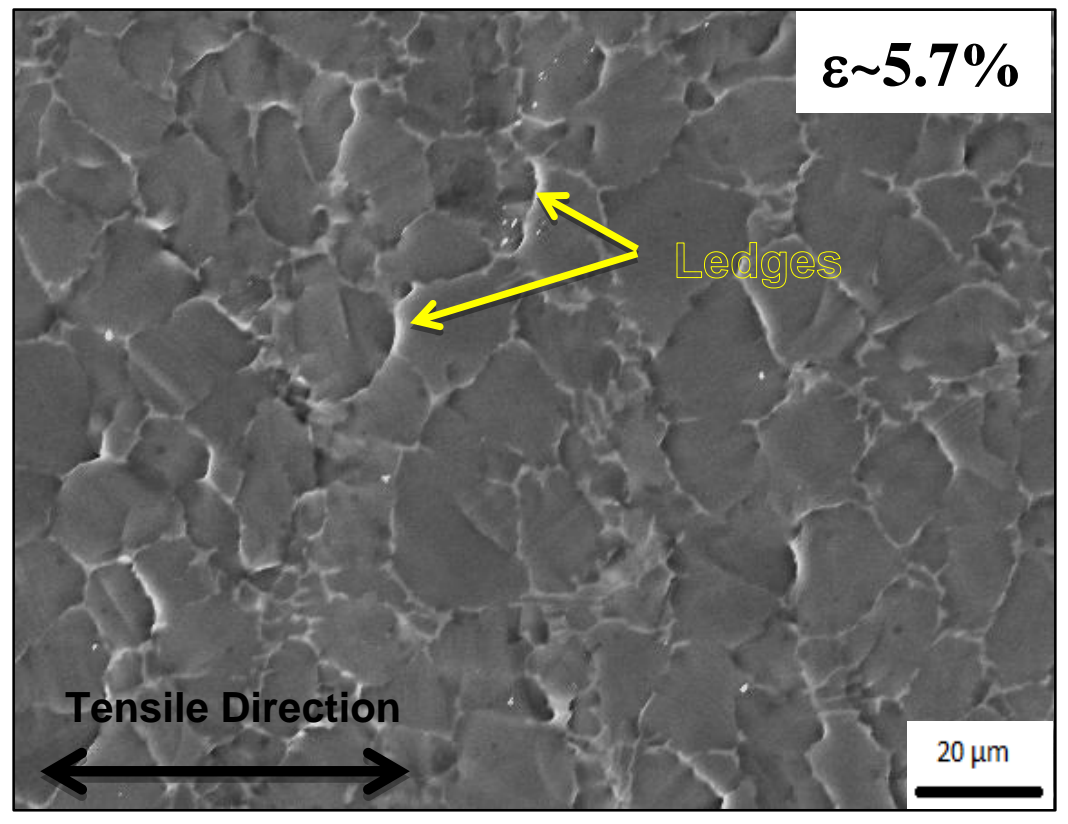

(b)

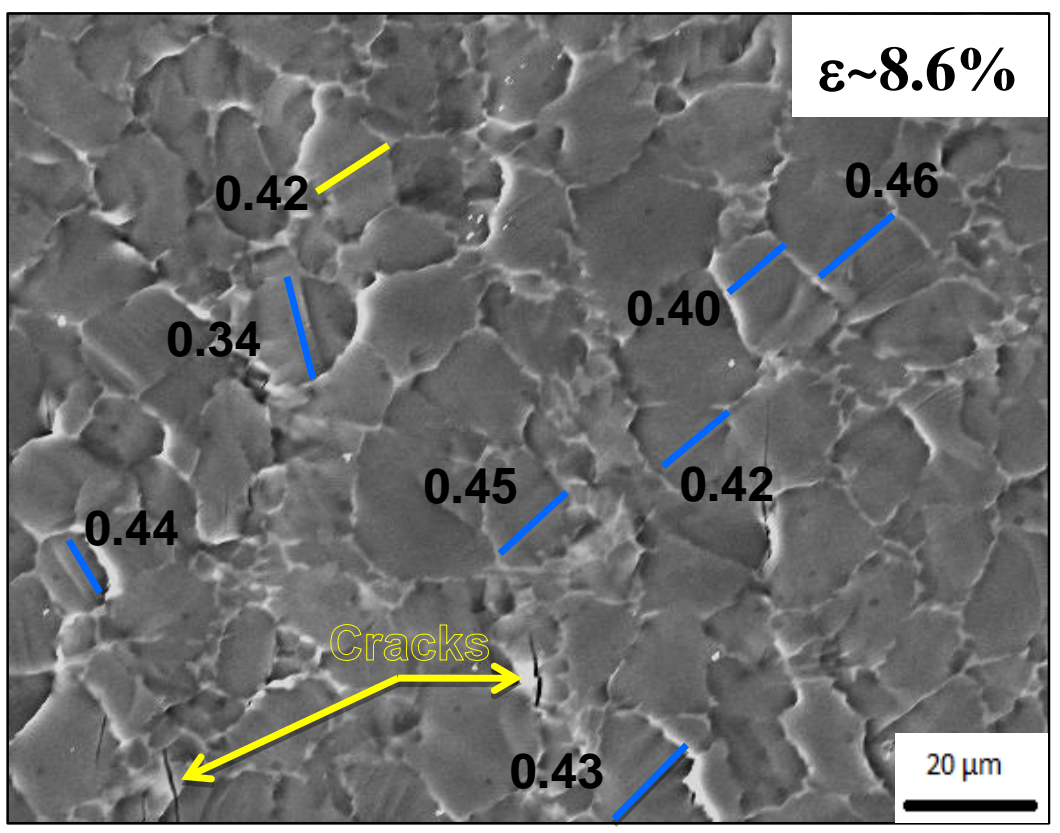


(c)
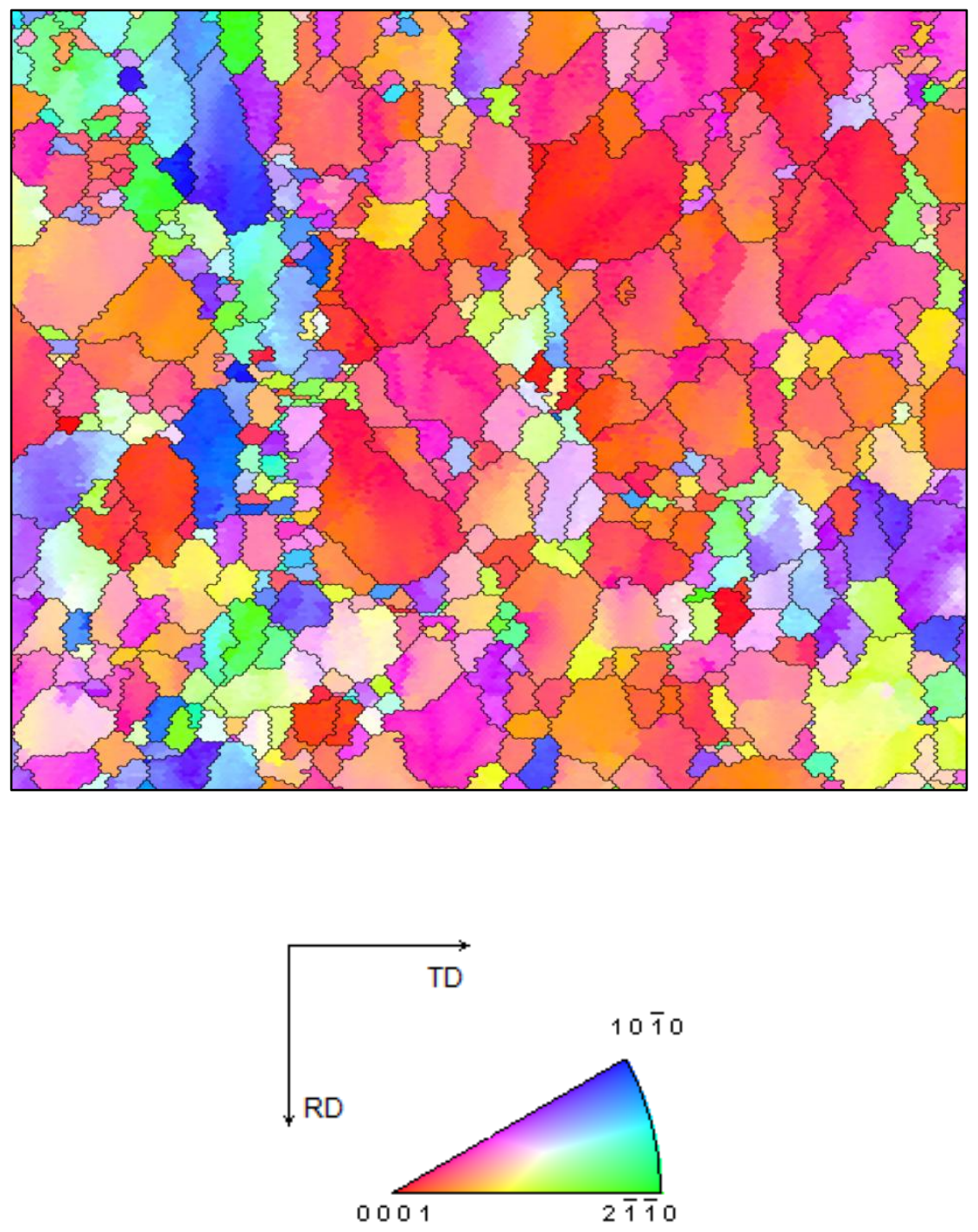

Figure 12. Sequential SE SEM images for the $370^{\circ} \mathrm{C}-440 \mathrm{MPa}$ tensile-creep tested specimen: (a) $\sim 5.7 \%$ strain, (b) $\sim 8.6$ strain. The EBSD orientation map of the sample before the test is provided in (c). In (b), slip traces are color coded for pyramidal slip (yellow), basal slip (blue), and associated Schmid factors are indicated next to the slip traces. 


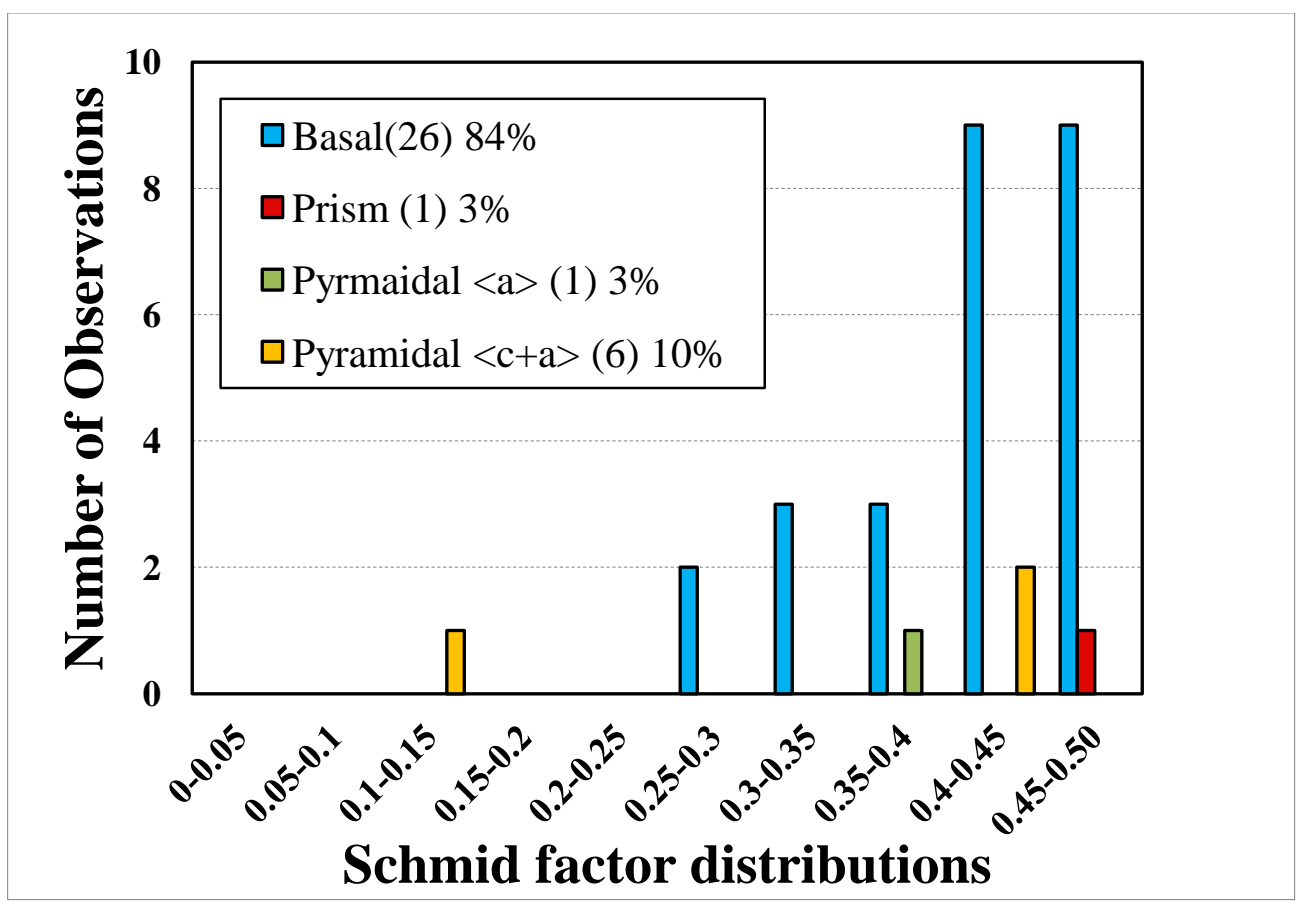

Figure 13. A histogram of the Schmid factor distribution of basal, prismatic, pyramidal $<\mathrm{a}>$, and pyramidal $\langle\mathrm{c}+\mathrm{a}\rangle$ slip modes for the $370^{\circ} \mathrm{C}-440 \mathrm{MPa}$ tension-creep sample deformed to $\sim 8.6 \%$ strain. The numbers in parenthesis indicated the number of grains which exhibited slip traces for that particular deformation mode. 

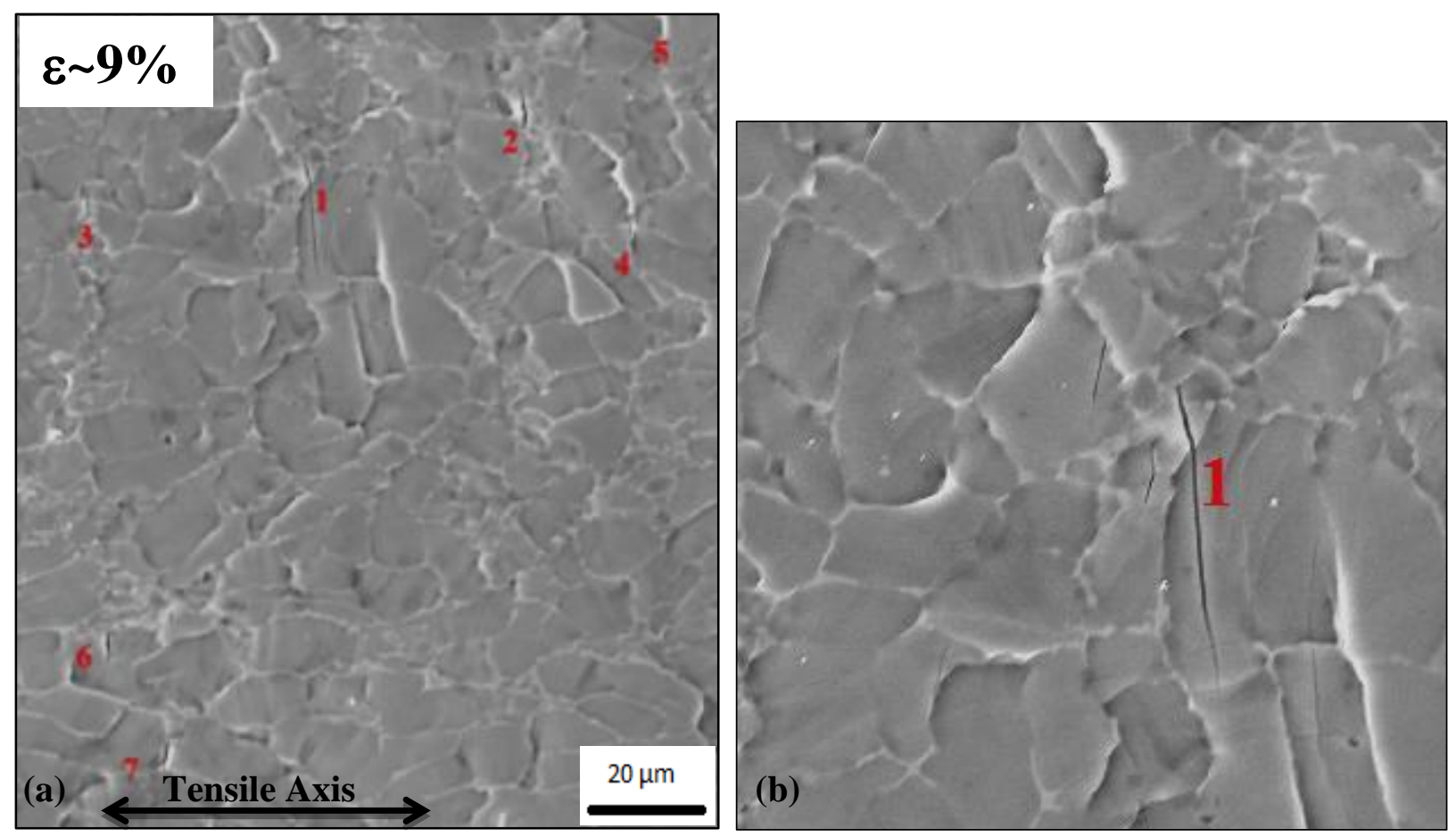

Figure 14. (a) A low-magnification SE SEM images for the $370^{\circ} \mathrm{C}-440 \mathrm{MPa}$ tensile-creep tested specimen showing cracking ( $9 \%$ strain), where the cracks are numbered 1-7. (b) A highermagnification image of the crack labeled " 1 ". 
(a)

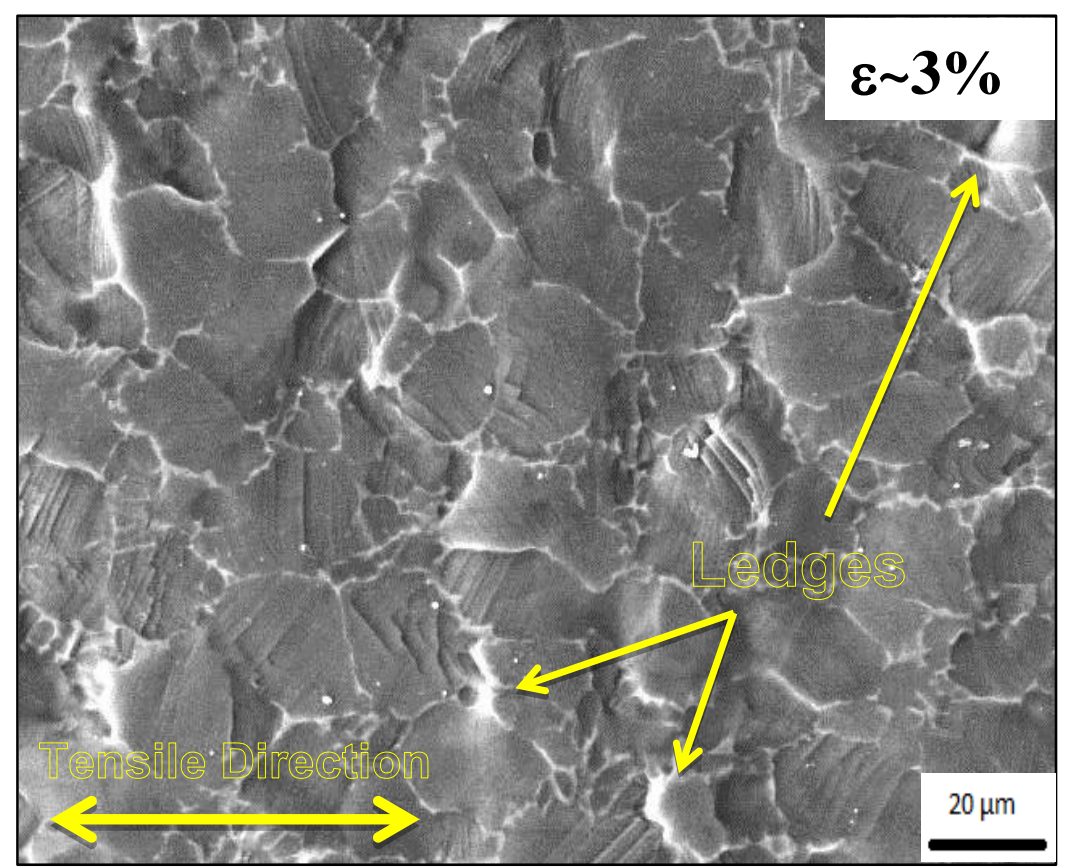

(b)

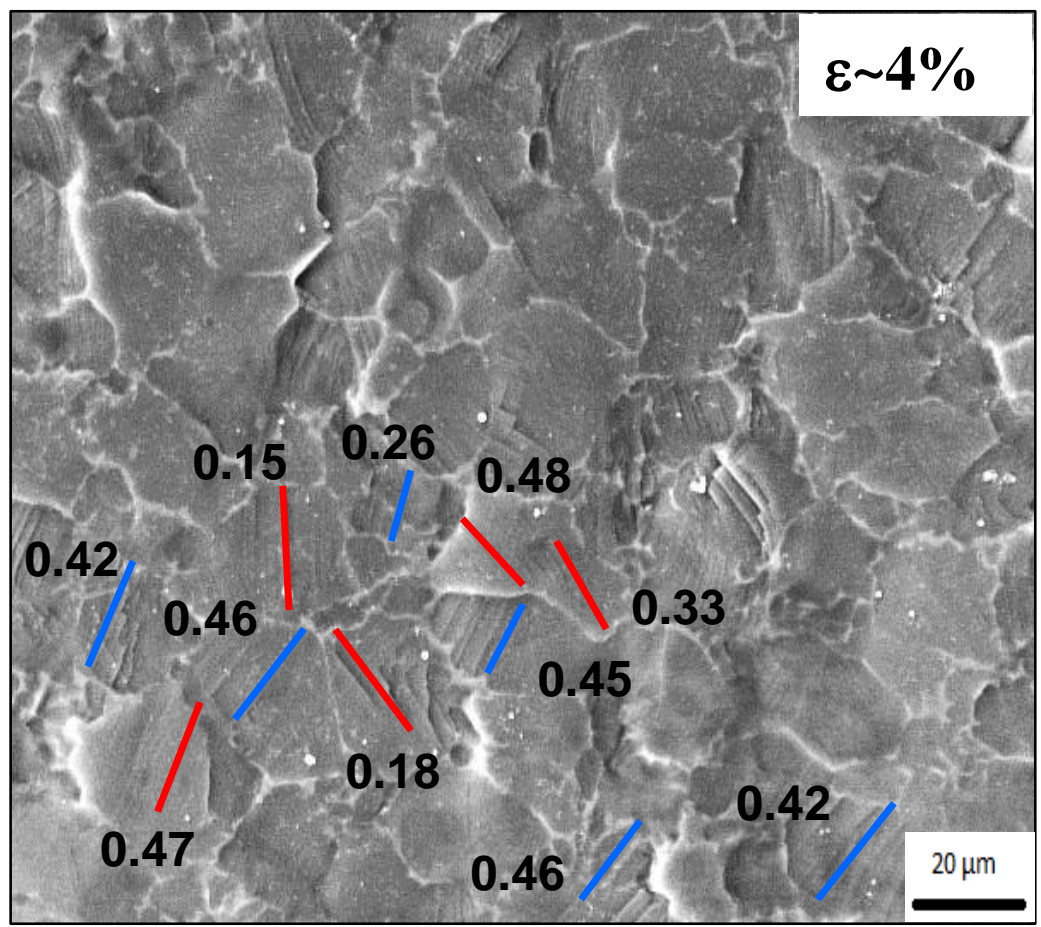


(c)
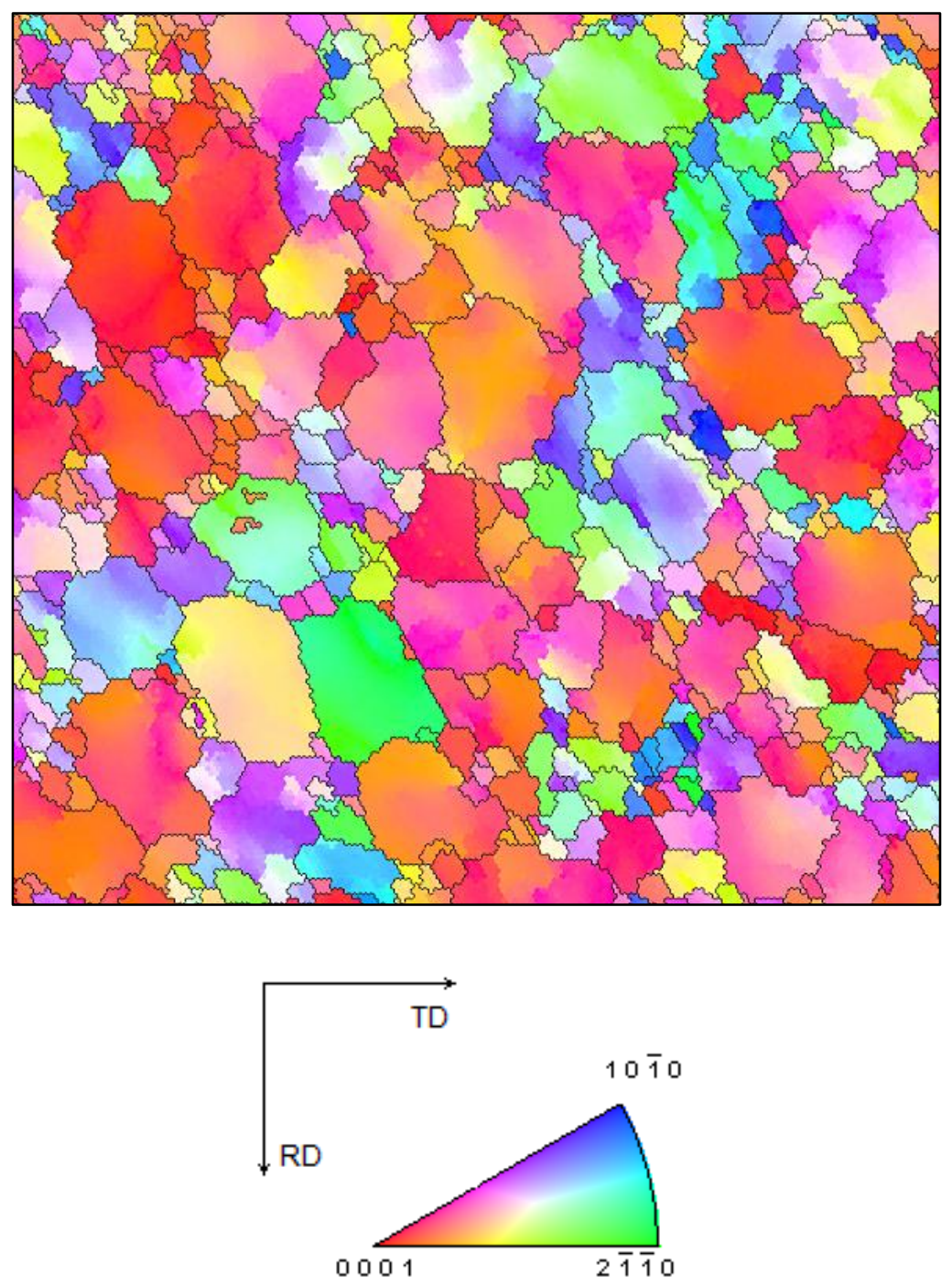

Figure 15. Sequential SE images for the $455^{\circ} \mathrm{C}-315 \mathrm{MPa}$ tensile-creep tested specimen: (a) $\sim 3 \%$ strain, (b) $\sim 4 \%$ strain. The EBSD orientation map of the sample before the test is provided in (c). In (b), slip traces are color coded for prismatic slip (red), basal slip (blue), and associated Schmid factors are indicated next to the slip traces. 


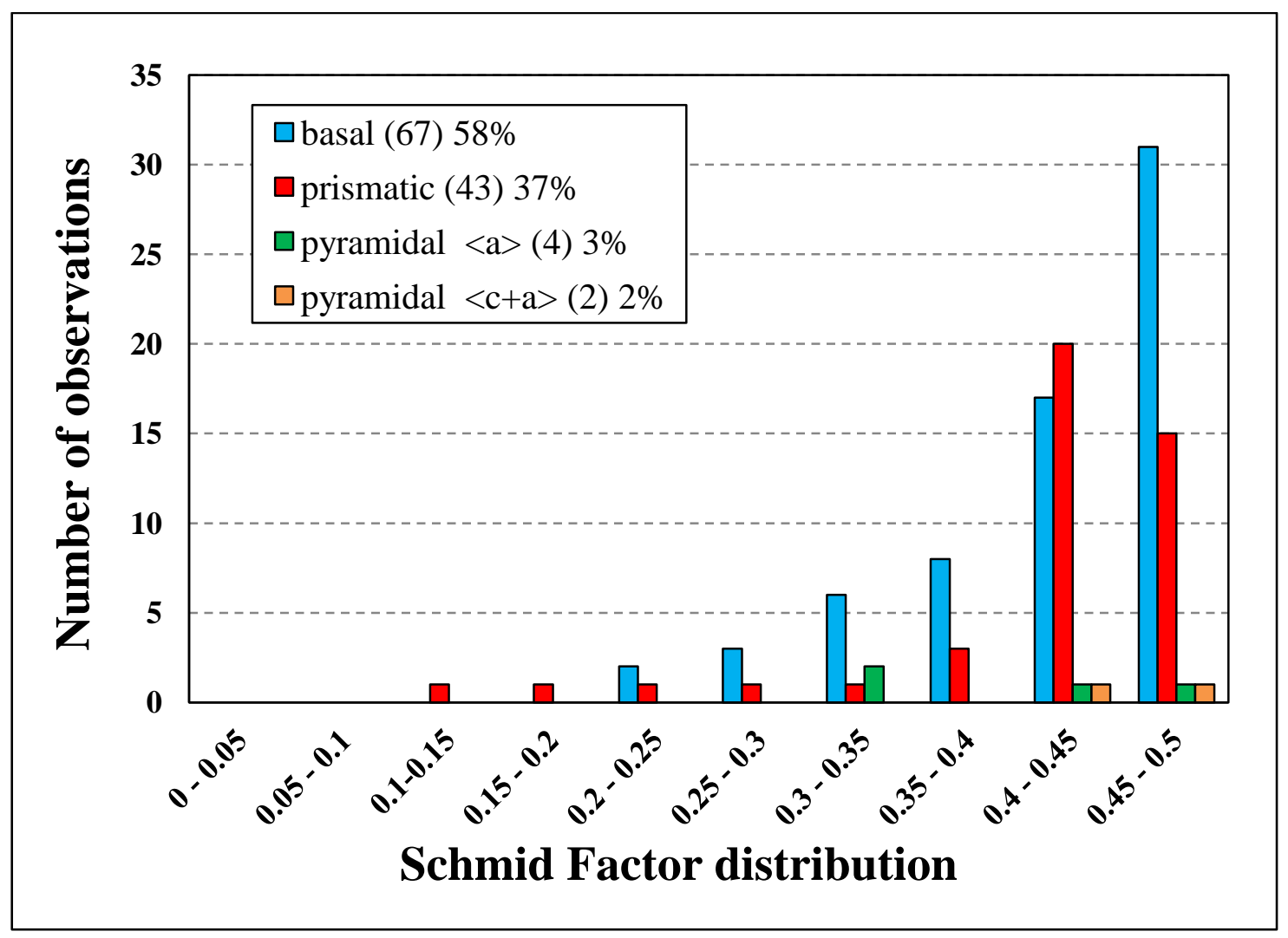

Figure 16. A histogram of the Schmid factor distribution of basal, prismatic, pyramidal <a>, and pyramidal $<\mathrm{c}+\mathrm{a}>$ slip modes for the $455^{\circ} \mathrm{C}-315 \mathrm{MPa}$ tension-creep sample deformed to $\sim 4 \%$ strain. The numbers in parenthesis indicated the number of grains which exhibited slip traces for that particular deformation mode. 